NBER WORKING PAPER SERIES

\title{
INVESTING OUTSIDE THE BOX: EVIDENCE FROM ALTERNATIVE VEHICLES IN PRIVATE CAPITAL
}

\author{
Josh Lerner \\ Antoinette Schoar \\ Jason Mao \\ Nan R. Zhang \\ Working Paper 24941 \\ http://www.nber.org/papers/w24941
NATIONAL BUREAU OF ECONOMIC RESEARCH
1050 Massachusetts Avenue
Cambridge, MA 02138
August 2018

We received helpful comments from participants at the Fiduciary Investments Symposium and the London Business School Private Equity Symposium, as well as Sabrina Howell, Mark Kritzman, Filippo Mezzanotti, and Andrea Rossi (discussant). We thank Arnold May and Robin Painter of Proskauer Rose for helpful conversations about fund structuring. We thank Will Kinlaw and J.R. Lowry for their support of this research. Harvard Business School's Division of Research, the Private Capital Research Institute, and the Smith-Richardson Foundation provided financial support for this project. Lerner and Schoar have advised institutional investors in private capital funds, private capital groups, and/or governments designing policies relevant to private capital. State Street provides a variety of custodial and financial services for limited and general partners in private capital funds, as well as offering private capital financial products. All errors and omissions are our own. The views expressed in this material are the views of the authors. They do not necessarily represent the official views of State Street Global Exchange, State Street Corporation and its affiliates, and the National Bureau of Economic Research.

NBER working papers are circulated for discussion and comment purposes. They have not been peerreviewed or been subject to the review by the NBER Board of Directors that accompanies official NBER publications.

(C) 2018 by Josh Lerner, Antoinette Schoar, Jason Mao, and Nan R. Zhang. All rights reserved. Short sections of text, not to exceed two paragraphs, may be quoted without explicit permission provided that full credit, including $\odot$ notice, is given to the source. 
Investing Outside the Box: Evidence from Alternative Vehicles in Private Capital Josh Lerner, Antoinette Schoar, Jason Mao, and Nan R. Zhang

NBER Working Paper No. 24941

August 2018, Revised September 2018

JEL No. G1,G2

\begin{abstract}
$\underline{\text { ABSTRACT }}$
This paper undertakes a comprehensive analysis of alternative investment vehicles in private equity, using unexplored custodial data about 112 limited partners over four decades. We differentiate between alternative vehicles that are GP-directed versus those where the LP has some discretion. Of the roughly 5500 distinct investments made by the LPs in our sample, $32 \%$ of investments (17\% of capital commitments) were in such alternative vehicles; the allocation increased by more than 10 percentage points over the last decade. Alternative vehicles were far more likely to be offered by larger and North America-based buyout funds. The average performance of these alternative vehicles lagged that of the GPs' corresponding main funds. The best LP performance was among endowments, private pensions, and insurers. Finally, LPs with better past performance invested in alternative vehicles with better performance, even after conditioning on the GPs' past records. This result suggests that bargaining between GPs and LPs leads to gradation in investment performance based on the parties' outside options.
\end{abstract}

Josh Lerner

Harvard Business School

Rock Center 214

Soldiers Field

Boston, MA 02163

and NBER

jlerner@hbs.edu

Antoinette Schoar

MIT Sloan School of Management

100 Main Street, E62-638

Cambridge, MA 02142

and NBER

aschoar@mit.edu
Jason Mao

State Street Global Exchange

100 Summer Street

Boston, MA 02110

XMao@ statestreet.com

Nan R. Zhang

State Street Global Exchange

140 Mt Auburn Street

Cambridge, MA 02138

United States

nzhang2@ statestreet.com 


\section{Introduction}

Financial intermediaries offer an array of services to institutional and individual investors. Foremost among these is their superior ability to gather and act on information, a point that has been emphasized in a number of important theoretical papers (e.g., Leland and Pyle, 1977; Diamond, 1984; Admati and Pfleiderer, 1994). At the same time, financial intermediaries display significant heterogeneity in their performance, which may be driven by differences in managers' ability to identify and access the best investments, as well as by the fees that they charge for their services. In public markets, a large literature suggests that managers of actively managed mutual fund funds do not persistently outperform passively managed ones, which consequently has led to a shift of many investors towards passive funds with much lower fees (e.g., Khorana, Servaes, and Tufano, 2009; Cremers, et al., 2016).

In private capital markets, the dynamics are somewhat different. On the one hand, asset owners investing in private markets have expressed similar concerns about the high levels of fund manager compensation, which, they have argued, has led much of the surplus from these investments being garnered by the fund managers. Public discussions of this issue (and of the need for more favorable fund economics) date back at least as far as a controversial study that a number of large United States public pensions commissioned in the mid-1990s (Mercer, 1996). Academic studies have similarly documented the substantial magnitude of fees and the large wedge between gross (pre-fee) and net (realized) returns of investors (e.g., Gompers and Lerner, 1999; Metrick and Yasuda, 2010; Phalippou, Rauch, and Umber, 2016). But despite these concerns, there has 
been relatively limited competition across private capital managers in the pricing of their main funds (see Gompers and Lerner, 1999; Metrick and Yasuda, 2010).

On the other hand, and differently from public markets, there is a widespread belief that manager skill in private equity drives performance and allows some funds to persistently outperform the industry. The wide dispersion and persistence in private equity returns has been well documented (Kaplan and Schoar, 2005; Metrick and Yasuda, 2006). These differences in perceived skill affect the bargaining power of GPs and their ability to attract capital. But there also seem to be differences in the desirability of LP investors: for instance, some might have more connections or deeper pockets to provide GPs with "liquidity insurance" in bad times (see for example, Lerner and Schoar, 2004). In an important paper, Berk and Green (2004) suggest that if managers differ in their skill and operate with a decreasing returns-to-scale technology, higher skill managers will manage larger funds and extract more rents. In the Berk-Green model, all funds will provide identical marginal returns to investors, since investors are homogenous. If instead LPs also differ in their attractiveness and sophistication, there will be heterogeneity in the bargaining power of both LPs and GPs. More powerful and attractive LPs should match with better GPs. And within the fund offerings of a given GP, we would expect differentiation in the structures that are offered to LPs of different types. Better LPs should more likely be invited to participate in vehicles with better terms and better performance, holding constant GP quality.

Across their portfolios, private capital groups can achieve this differentiation of fund returns by adjusting either transaction fees or asset quality across investment vehicles. The best groups may not need to offer discounted separate accounts or co-investments at all. These top GPs 
might not be willing to dilute the quality of their main fund, perhaps for reputation reasons, or because their own investment professionals are major investors. However, since many of these groups have significant excess demand by LPs would like to invest with them, they might be willing to set up alternative vehicles which might allow less premier LPs to invest with them. These LPs might be willing to accept slightly lower returns on investment from these LPs, since their outside options are also lower than for the top LPs. Of course, all LPs might not be that rational. Due to the opacity of private capital, some LPs may not understand that they are being offered inferior opportunities. Thus, asset owners who aggressively pursue discounts may find that they paradoxically end up with lower returns.

The evolution of private equity fund structures over the last decade and a half seems to be well characterized by this model. Case studies and practitioner accounts suggest that certain highprestige investors - for instance, the Harvard endowment (Hardymon, Nicholas, and Fouka, 2014) and the Canadian Pension Plan Investment Board (Lerner, Rhodes-Kropf, and Burbank, 2013) — have long demanded co-investment opportunities and special terms when investing in partnerships. ${ }^{2}$ A key response by private capital groups to LP pressures has been to offer a broader set of selected investors opportunities to access their investments in non-traditional ways. Many fund managers have become increasingly creative in terms of offering selected investors products "outside the box."

\footnotetext{
${ }^{2}$ Similarly the Teachers Retirement System of Texas (Rhodes-Kropf, et al., 2014) undertook a series of ten-figure investments with alternative investment groups on highly favorable terms.
} 
Despite the intense real-world interest in investment strategies using alternative vehicles, assessing the extent and success of these approaches has been challenging. The performance of alternative vehicles is rarely reported in official disclosures by fund managers. Even the services that track these markets, such as Burgiss, Cambridge Associates, and Preqin (see the overview in Brown, et al., 2015), focus on documenting the performance of main funds rather than alternative vehicles. The only exception are studies which focus on select samples of direct investments by limited partners: Fang, Ivashina, and Lerner (2015) analyzed co-investments and solo investments using information from only seven large (and undoubtedly non-representative) limited partners, while Braun, Jenkinson, and Schemmerl (2017) looked at co-investments recorded in the CapitalIQ database, which only captures a (potentially non-random) selection of transactions.

In this paper, we explore a much more comprehensive data set, covering investments into entities organized by private capital funds for 112 asset owners. To do this, we use the records of State Street Corporation, which plays a custodial role for these asset owners. The data captures all cash flows between limited partners and the private capital fund managers in their portfolios. In total, the data set includes over one half-trillion dollars of commitments in twenty thousand distinct investments by individual LPs between 1980 and mid-2017. We focus on three categories of vehicles, which we define in detail below: main funds of a general partnership, discretionary vehicles such as co-investment transactions, and GP-directed vehicles.

We first document a set of stylized facts concerning the evolution of alternative investment vehicles in private equity during our sample period: 
- Capital Allocation: The allocation of capital to alternative vehicles has been growing over time. In the 1980 s, $91 \%$ of the vehicles raised and $93 \%$ of the capital commitments were to main funds. In the 2010 s, these shares fell to $64 \%$ and $76 \%$ respectively. The use of alternative vehicles is widespread. For instance, of the 108 asset owners investing in private capital in the sample (four made no such investments), 87 invested in GP-directed and 69 in discretionary vehicles.

- Vehicle Types: Alternative investment vehicles can be broadly categorized into what we term discretionary and GP-directed vehicles. The former are comprised of co-investment opportunities that are provided by a GP but in which the LP maintains discretion over which deals to invest. The latter typically are funds that invest in similar securities as the main funds, where the GP retains key decision-making powers. Of the roughly 5500 distinct vehicles attracting investments, $32 \%$ by number and $17 \%$ by capital commitments were what we term discretionary and GP-directed vehicles.

- Performance: In the cross section, the average performance of alternative vehicles was very similar to the average main fund in our sample. The one exception was the ratio of total value to paid-in capital (TVPI), where main funds performed substantially better. When comparing the performance of alternative vehicles to those of the main funds raised by the same private capital group in the same year (or in the five years prior), we see that on average the alternative vehicles underperform their associated main funds. Using weighted average PME performance, discretionary vehicles underperform, by 0.016 and GP-directed funds underperform by 0.101 , with only the latter being statistically significant. When breaking out the results on size-weighted performance by decade, we 
further find that discretionary investments did particularly poorly in the 2000s, while GPdirected vehicles underperformed their main funds especially after 2010.

- Composition: Alternative vehicles were far more likely to be offered by buyout funds than venture capital ones, comprising $38 \%$ of all vehicles and $18 \%$ of all capital raised by buyout-focused groups; but only $20 \%$ of vehicles and $10 \%$ of capital raised by venturefocused ones. A corollary is that the tercile of the largest GPs raised 18\% of their capital through alternative vehicles, as opposed to $2 \%$ by the tercile of smallest funds.

In a second step, we provide evidence consistent with the idea that alternative vehicles can be seen as the result of a bargaining process between a set of heterogeneous GPs and LPs in the private equity market. In line with our discussion above, we find that partnerships with higher past PMEs were able to raise more capital in both their main funds and side vehicles relative to GPs with lower PMEs. The average performance of alternative vehicles offered by high-PME partnerships outperformed the average fund in the market. In contrast, those of low-PME partnerships performed more poorly. But when looking at the relative performance of the different types of alternative vehicles benchmarked against the main funds of these GPs, we see that GPdirected vehicles significantly underperformed their main fund, especially for top performing GPs, while discretionary vehicles outperformed even the main fund. If we believe that discretionary vehicles are typically offered only to the best LPs, the results support the idea that GPs differentiate the returns they offer to different type of investors.

In further support of the bargaining interpretation, we also find that LPs with better past performance invested in alternative vehicles that had above average market performance: indeed, 
these side vehicles even outperformed the main fund of the GP sponsoring these alternative vehicles. In addition, the categories of LPs that have the highest performance in their alternative vehicle investment were those that are typically seen as high-prestige LPs, such as endowments and foundations, private pension funds, and insurance companies. The poorest performance in alternative vehicles was seen for fund-of-funds. We also find that larger LPs and North America based LPs were less likely to resort to alternative vehicles, while European LPs are more likely to invest in these vehicles, even controlling for other LP characteristics. This again might suggest the idea that LPs whose access to the top funds is more limited-i.e., those whose bargaining power is lower--were more likely to invest in alternative vehicles.

Finally, we show that there was an interaction between the past performance of the LPs and GPs. We classify GPs and LPs by the average performance of their portfolio across all VCPE investments and test how the performance of the alternative vehicles varied with the quality of the match between LP and GP, e.g., a top-performing LP investing in a top-performing GP, and so on. The results show that alternative vehicles have the highest performance on average if the LPs and GPs involved in the vehicle were both above-median performers. Alternative vehicles where both LP and GP are below-median performers had the worst performance. And the off-diagonal matches (top LP,-below median GP, and vice versa) perform at intermediate levels. These results support the idea that GPs tailor the alternative vehicles they offer their LPs to the outside options of the LP. Controlling for the type of GP, better LPs get better returns and vice versa for lowerperforming LPs. 
The rest of this paper is structured as follows. Section 2 describes the creation of the data set. Section 3 presents the usage of and analyzes the performance of alternative vehicles in general. Section 4 presents analyses across different classes of general partners and limited partners. The final section concludes the paper.

\section{Constructing the Sample}

\section{A. State Street}

The data in this paper consists of cash flow from the records of State Street Corporation's custodial unit, which provides services for asset owners, including pensions, sovereign wealth funds, and endowments. As of the end of third quarter of 2017, State Street's custody business had \$32.1 trillion of assets under ownership and control, just behind the largest custody bank, Bank of New York Mellon. ${ }^{3}$ State Street also provides custodial services to fund managers and other clients, as well as engaging in asset management, securities trading, and securities finance.

Among the custodial services that State Street (and other custodial banks) provide to their asset owner clients are keeping track of the securities held, tracking cash flows between the investors and fund managers, executing the sales of securities and other transactions, assisting with foreign currency conversions, and documenting the investors' activities, including for tax purposes. (For an industry overview, see Clearing House, 2016.) Thus, in their role as a custodian, State Street has a comprehensive picture of the investments made by the asset owners that they

\footnotetext{
3 "State Street Challenging BNY Mellon As Largest Custody Bank," Forbes, November 16, 2017, https://www.forbes.com/sites/greatspeculations/2017/11/16/state-street-challenging-bny-mellonas-largest-custody-bank/\#1b6e90af63f2.
} 
work for. All cash flows are recorded net of management fees and carried interest charged by the general partners.

\section{B. The Data Set}

State Street's custodial division has a rich array of data on its clients. The 108 asset owners with private capital exposure have invested into over seventy thousand private financial vehicles of various types, which include private equity, real estate, hedge funds, securitizations, and many other assets. For the purposes of this paper, we focus exclusively on private capital funds (buyout, private debt, and venture capital).

Identifying and classifying the vehicles associated with these private capital groups may sound straightforward, but in actuality is quite challenging. For example, TPG Global Advisors' July 2017 filing of Firm ADV with the U.S. Securities and Exchange Commission identified in Section 7B nearly 100 affiliated entities. ${ }^{4}$ While some of these were clearly identifiable from their titles (e.g., TPG Parallel III), many had far less obvious names (e.g., Arrow Ridge Capital Master Fund, FoF Partners III-B, and MLS (B\&C) AIV 1-B).

Moreover, there is not a clear mapping between the titles of these instruments and their characteristics. Labels like special purpose vehicle (SPV) and affiliated investment vehicle (AIV) are used by GPs in a seemingly random fashion. Thus, classifications could not be done on the

\footnotetext{
${ }^{4}$ TPG Global Advisors, "Form ADV: Uniform Application for Investment Adviser Registration and Report by Exempt Reporting Advisers," July 19, 2017, https://adviserinfo.sec.gov/IAPD/content/ViewForm/crd_iapd_stream_pdf.aspx?ORG_PK=1597 32.
} 
basis of fund name, but required manual review. To illustrate the difficulty, AIVs frequently fell into two categories. The first type, often referred to as a "subsidiary AIV," was owned directly by the fund (either in whole or in part with other LPs). Subsidiary AIVs typically held a set of investments that mirrored the find with which it is paired. The second kind of AIV, usually called a "side AIV," was not owned by the fund, but rather by a subset of the fund's partners, including the GP. This type of AIV typically co-invested in selected portfolio companies (or a portfolio company) alongside the fund.

Using State Street's internal classification scheme for investment vehicles in its State Street Global Exchange (GX) Private Equity Index (PEI) database, we identify 22 thousand of the seventy thousand transactions that appear to be private equity-related. The index covers around three thousand funds over a thirty-year period, and is used by some of the world's largest investors to benchmark their private equity portfolios. Thus, we exclude many investments made by asset owners into vehicles organized by hedge and real estate groups without private equity funds.

Using State Street's "standardized name convention" process, we identified 6,068 unique investment vehicles with associated LP and GP names. (In many cases, multiple LPs in the database invested in the same vehicle.) We also included in this total a number of vehicles that did not have a GP affiliation due to the nature of vehicle, especially what Fang, Ivashina and Lerner [2015] term "solo" investments by LPs. We then filtered out 746 of these vehicles, including real estate funds, hedge funds, traditional funds-of-funds and secondary funds, and other non-PE vehicles (which are not the focus of this research paper). 
We examined the remaining 5,322 vehicles. We associated them with general partners and classified them into three main categories, based on various sources. The key resources we used were:

- The GXPEI database, which contained identifying links between vehicles and funds. Even when there was no identifier, often a text note or other identifier indicated which private capital group and/or fund the vehicle was associated with and its characteristics.

- A list of vehicles associated with all private equity groups that we assembled from outside sources. We used the list to identify the unmatched vehicles listed in the database, as well as to determine their characteristics. The sources used to create the list included:

- SEC Exhibit 21s for publicly traded entities, which lists the names of affiliate and subsidiary entities. As SEC regulations note: "A list of subsidiaries must be disclosed to the SEC as Exhibit 21 to registration statements filed on Forms S-1, S4, S-11, F-1, F-4, 10, and the annual report filed on Form 10-K."

- We downloaded and analyzed all Form ADVs filed between 2001 and 2016. Since the passage of the Dodd-Frank Act, these forms must be filled out by all nonventure private equity with more than $\$ 150$ million in assets under management in the United States. Section 7B of Form ADV includes the names of all affiliated entities.

- Searches of the SEC database for keywords, "Affiliated Fund," "Co-invest," "Special Purpose Vehicle," "Special Investment Vehicle," "SPV," and "AIV." These searches generated a wide variety of documents filed by private equity

${ }^{5}$ U.S. Securities and Exchange Commission, Office of Investor Advocacy and Education, "Researching Public Companies through EDGAR: A Guide for Investors," no date, https://www.sec.gov/oiea/Article/edgarguide.html. 
groups listing affiliate structures, such as Form 400-APP/A, "Applications under the Investment Company Act other than those reviewed by Office of Insurance Products" and Form D.

- We finally undertook extensive research on the remaining unmatched entities to understand their properties and affiliations. The resources we used included fund web sites, media accounts, and the records in Preqin and Thomson Reuters (which sometime list a variety of alternative vehicles in addition to main funds).

Among the 5,322 investments, we were able to identify 3,620 "main funds" by matching and cross checking with State Street PEI database of PE partnerships. The majority of those in the database are contained in the State Street Global Exchange Index. Most main funds are traditional eight-to-ten year limited partnerships, but a few have less common structures, such as the longduration funds that a number of private equity groups have raised in recent years.

Of the remaining entities, they are split between what we term 819 GP-directed vehicles and 883 discretionary vehicles. We define these as follows:

- GP-directed parallel vehicles (henceforth GP-directed) typically invest in similar securities as the main funds and the GP retains key decision-making powers. These vehicles contain special features to cater to certain classes of limited partners. For instance, they may be tailored to:

○ have more favorable economics for a limited partner that is making a sizeable capital commitment, 
- avoid domestic tax obligations for non-domestic investors, such as blocker funds and offshore vehicles,

allow the GP to continue to finance firms when they are running out of capital in the main fund,

○ not use using capital call lines to address investors' concerns about risk, or

○ address many other limited partner concerns.

- Discretionary vehicles allow the limited partner to invest in one or more transactions. Under this category, we include a number of vehicles. These include co-investments into individual companies by one or more LPs; solo investments by LPs in previously private capital-financed companies; pledge fund structures where transactions are funded by the LP on a deal-by-deal basis (sometimes raised by groups that have encountered poor performance who have found raising a traditional fund difficult); co-investment or overage funds that are raised alongside a main fund; and co-sponsored transactions between LPs and GPs. We also include co-investment funds raised by funds-of-funds and other intermediaries (though not the traditional funds-of-funds or secondary funds that they raise). ${ }^{6}$ Many intermediaries have aggressively expanded into this area, especially after the widespread disillusionment with traditional funds-of-funds engendered by the Global Financial Crisis and the collapse of Bernard Madoff's hedge funds.

A natural question is the extent to which the State Street sample is subject to sample selection bias itself. For instance, State Street could have gained or lost customers for its custodial

\footnotetext{
${ }^{6}$ These co-investment funds run by funds-of-funds and other intermediaries may not allow that underlying asset owner to opt into individual investments. Thus, while the intermediary has discretion where to invest, the underlying LP may not.
} 
business that could have led to dramatic fluctuations in the comprehensiveness of coverage over time. One way to evaluate this concern is to examine the commitments to main funds in the sample. We compute the ratio of these capital commitments over time to total capital commitments to private capital funds. To compute the overall commitments, we use the total global private capital fundraising as estimated by Preqin from 1995 onward. For the years before 1995, we use estimates from a variety of sources, including Buyouts, the Private Equity Analyst, and the Venture Capital Journal for the U.S., the various Yearbooks of the European Venture Capital Association for Europe, the Asian Venture Capital Journal for Asia, various publications and reports of the Latin American Venture Capital Association, and the reports of McDonald \& Associates for Canada. Not all these sources go back to 1980; when they do not, we supplement the data series with estimates based on news stories, case studies, and trade journals.

This analysis suggests that State Street's clients have made a reasonably consistent share of the commitments to the main funds of private capital firms. The funds committed $2.4 \%$ of the capital to the funds in the 1980s (of course, the collective committed capital of the main funds in which they invested was a much larger share of the industry). In the subsequent three decades, the shares were $4.8 \%, 6.3 \%$, and $4.3 \%$. This broad look does not suggest dramatic fluctuations in coverage, though the coverage was clearly at a lower level during the 1980s than in subsequent decades.

\section{Alternative Vehicles: An Aggregate Look}

A. Distribution of Use 
We first look at the use of different vehicles in general. Table 1 provides an overview of the data set. Of the 108 asset owners active in private capital, fully 87 invest in GP-directed vehicles and 69 in discretionary ones. Looking at the number of distinct investments and the dollar size of the commitments, main funds represent $68 \%$ of the distinct vehicles and $83 \%$ of the capital committed. GP-directed and discretionary vehicles are roughly equal in number, but the former represent 50 billion dollars in capital to the latter's 38 billion. The difference stems not from the average size of the capital commitments, but rather from the number of investments.

Table 2 looks at the temporal distribution of the number of investments in and the dollar commitments to main funds and alternative vehicles. The observations are divided in Table 2 by the decade of the vehicles' formation (vintage year in industry parlance). The tabulation for the 2010s only runs until mid-2017. Two patterns are apparent from the table. The first is the acceleration of private capital activity over time. Dollar commitments to main funds and GPdirected vehicles increased 100-fold, and to discretionary vehicles more than 200 -fold. In part, this pattern may reflect State Street's increasing coverage of LPs after the 1980s. But as highlighted above, the primary driver of this pattern was that the increased allocation to private capital by LPs over time. Moreover, the share of alternative vehicles among the private capital commitments increased. As Panel B reports, the share of vehicles that were discretionary went from $6.6 \%$ in the 1980 s to $18.8 \%$ in the 2010 s; the share of capital committed to these vehicles went from $5.4 \%$ to $10.6 \%$. Among the GP-directed vehicles, the increase was from $2.6 \%$ to $16.9 \%$ of the vehicles, and $1.5 \%$ to $13.4 \%$ of the capital. 
Figures 1 and 2 depict these patterns graphically, focusing on the number of vehicles formed and capital commitments (note the two different scales in this graph) by vintage years. The ebbs-and-flows of fundraising — with the peaks of fundraising in 2000 and 2007-08, the crashes of 2001-02 and 2009, and the recovery in recent years - are readily apparent. The seeming downturn in activity in 2017 is driven by the fact that the total represents only part of the year's activity. While the volume of activity in alternative vehicles follows the pattern of the main funds, the increased share in recent years is apparent.

\section{B. Relative Performance}

We then turn to understanding the performance of these instruments. The first way to examine performance is to simply look at the returns from each class of vehicle. Table 3 presents their performance measured three ways: our baseline measure, the Kaplan-Schoar (2005) PME computed relative to the Russell 3000 , as well as two measures often used by practitioners, the internal rate of return (IRR) and the ratio of total value to paid-in capital. (Henceforth, the tables will exclusively focus on PMEs, as this is the standard performance measure used in the academic literature.) Recall that the State Street data report the cash flows actually realized by the limited partners. As it is difficult to validate some historical cash flow data, we dropped a modest fraction of the vehicles from the analysis.

In this table, we present several performance metrics. First, we use each vehicle as an observation: there is no added weight if multiple asset owners invested, or if the committed capital was relatively larger. We present in each case the $25^{\text {th }}$ and $75^{\text {th }}$ percentiles of performance, as well as the median returns. Second, we compute the weighted average performance, where the weights 
are the total capital commitments by all the LPs in the State Street population who invested in the same vehicle.

Table 3 shows that there are limited differences between the performances of the three classes of vehicles. The median discretionary and median GP-directed vehicle performed slightly better than the median main fund in terms of PME; though the pattern is reversed at other reported quartiles. The patterns in the other performance measures are also mixed. Discretionary and GPdirected vehicles outperform in terms of IRR, but one of the sharpest differences is the higher TVPI for main funds (1.37 versus 1.26 and 1.26). This last result may reflect that main funds are on average more mature, given the increased popularity of alternative vehicles in recent years. The dominant impression is the absence of a significant differences in the performance of the different vehicles in aggregate.

One natural question relates to the seeming deviation between the relatively low PMEs generated by our portfolio of main funds and those reported in canonical studies such as Harris, et al. (2016). These differences spring from five variations: (a) the calculation of performance through mid-2017, (b) the inclusion of private debt funds in addition to venture and buyout ones, (c) the inclusion of funds based outside the U.S., (d) the usage of the Russell 3000 rather than the S\&P 500, and, most importantly, (e) the inclusion of recent vintage years. If we repeat the calculations in Exhibit II of Harris, et al. - that is, only using U.S. funds in vintage years through 2010 and comparing performance against the S\&P 500, but calculating performance through mid2017—we obtain very similar numbers to theirs. For instance, our average PME for buyout funds across all vintage years (calculated using 944 funds, to their 781) is 1.22, as compared to their 
1.20. Our average PME for venture funds (computed using 669 funds, to their 1095) is 1.44, as compared to their 1.35. We present the computations for main funds with these adjustments in Appendix B.

Figure 3 looks at the temporal patterns in performance. Focusing on Panel A, which presents the PME-based measures, we see that the return series of the various vehicles tend to track each other by-and-large. The returns of alternative transactions-which may reflect their less diversified nature - are more volatile than the others. Particularly noticeable are the high PMEs from discretionary investments made in 2009-10, a point also made in practitioner accounts (Leamon, Lerner, and Bosiljevac, 2012).

This comparisons in Table 3 and Figure 3 may be misleading, however, because not all private capital groups raised alternative vehicles; and not all investors can invest in all vehicles separately from the main fund. In particular, one might anticipate that asset owners might be disinterested in undertaking discounted arrangements with poorly performing fund managers, while top-tier private capital groups might be unwilling to make such concessions.

Table 4 presents what we believe to be a more reasonable comparison. We look at the performance of the alternative vehicles against the main fund that investors presumably could have (or did) also invested in. We compute the difference in the PME between the performance of each alternative vehicle (again computing PMEs using the Russell 3000) and that of the main fund(s) raised by the same group immediately prior to the launch of the alternative vehicle. $58 \%$ of the alternative vehicles are matched to a main fund begun in the same year as the vehicle; $86 \%$ to one 
in the year of the fund or the two years prior. If there are no main funds raised in the previous five years, we do not use the alternative vehicle in the analysis. (Thus, the sample size shrinks from 883 to 725 for the discretionary vehicles, and from 819 to 708 for the GP-directed vehicles. ${ }^{7}$ ) Because there are a few extreme outliers, we winsorized the PMEs at the $0.5 \%$ and $99.5 \%$ level. We use a similar methodology in subsequent tables when reporting performance.

The results are robust to the use of alternative methodologies. One approach is to limit the matches to funds formed in the year of the transaction or the three years prior, which only eliminates $7 \%$ of the observations and has little impact on the results. A second approach is that if there are multiple main funds during the five years after the observation, we average the performance of the main funds and use this in the comparison. This methodology tends to depress the performance of the alternative vehicles to a certain degree.

We again look at the simple mean and median of returns across vehicles (counting each vehicle as a single observation), and then the average returns when weighting each by the size of the State Street LPs' capital commitments to that vehicle. We term this the Unadjusted Excess PME Performance of the alternative vehicles.

The results in Table 4 suggest significant underperformance by the alternative vehicles relative to their main funds. The underperformance is particularly stark when we examine weighted average performance, where the average discretionary vehicle underperforms by a PME

\footnotetext{
7 The exceptions are when we utilize raw returns in Table 3, Panel B of Table 15, and Table 23, where we winsorize the return data at the $99^{\text {th }}$ percentile.
} 
of 0.02 , and the average GP-directed vehicle by 0.12 (only the underperformance of the GPdirected vehicles is significant). The simple means and medians are insignificant and much closer to zero, suggesting that the underperformance is being made more extreme due to the largest transactions.

One concern with this methodology is that the alternative vehicles may be raised in later years than the main fund to which it is paired. As Harris and co-authors (2016) document, PMEs have been generally falling over time. This pattern may lead to the seeming underperformance of the alternative vehicles, simply because they were often raised in later vintage years than their paired main funds. While this correction may be excessively conservative (e.g., it may be appropriate to pair a co-investment made in 2007 with the 2004 fund which invested alongside the LP), we correct for the changing investment climate across the various vintage years. To do this, we compute what we term the Adjusted Excess PME Performance of the alternative vehicles. This measure is defined as follows:

$$
\text { (PME(AV) - Mean PME(MFs, VYAV)) - (PME(PMF) - Mean PME(MFs, VYPMF)) }
$$

where $\mathrm{PME}(\mathrm{AV})$ is the PME of the alternative vehicle, Mean PME(MFs, VYAV) is the mean PME of all main funds of the same vintage year as the alternative vehicle, PME(PMF) is the PME of the paired main fund, and Mean PME(MFs, VYPMF) is the mean PME of all main funds of the same vintage year as the main fund that is paired to the alternative vehicle. If the alternative vehicle and the paired main fund are contemporaneous, the unadjusted and adjusted excess performance will be identical. In other cases, this adjustment will correct for the differences in investment climate between the two years. 
Table 5 summarizes the performance using this adjusted measure. The results are similar, if slightly weaker. When using what we regard as the best approach, the weighted average, the discretionary and GP-directed funds continue to underperform their paired main funds, with PMEs that are 0.016 and 0.101 lower. This pattern suggests again that underperformance is more significant among the larger transactions. These patterns are depicted graphically in Figure 4, which depicts the distribution of the unadjusted and adjusted performance of the alternative vehicles of the two types relative to main funds.

We look at the robustness of the results reported in Tables 3 through 5 in Appendices $\mathrm{C}$ through E. In these supplemental tables, we exclude private debt funds (which are often not considered in the private equity literature), funds formed after 2011 (whose performance may still be difficult to discern), and blocker and offshore funds (whose performance might be affected by tax considerations). We find that these exclusions have little impact of the alternative vehicles' relative performance.

Table 6 summarizes the distribution of relative performance of alternative vehicles by decade. All three decades summarized (the returns during the 1980s are not tabulated due to the small sample size) were characterized by negative returns using weighted averages. The 1990s saw the most extreme underperformance. The simple average and median returns in the 2000 s and 2010s were positive. An intriguing pattern is the substantial uptick in performance of the discretionary transactions between the 2000s and 2010s, which move from significantly underperforming to significantly outperforming. The performance of the GP-directed transactions is poor during both periods. 


\section{Who Uses Alternative Vehicles}

We now turn to examining the differences between the use and performance of alternative vehicles across the general partners in the sample. We ask which types of partnerships rely more heavily on such alternative vehicles and what the returns are that they offer to their investors.

Table 7 summarizes the basic characteristics of the general and limited partners. The average GP in the sample was established in 2003, while the mean LP was somewhat older (1998). (Note that we use in calculating LP age the date of the asset owner's first private capital commitment, not the date of the organization's formation.) The total capital commitments garnered over their existence by the GPs from the custodial LPs vary widely, with a mean of just over six hundred million. The mean LP has committed $\$ 4.7$ billion to private equity. ${ }^{8}$

\section{A. Univariate Patterns across General Partners}

We first start by looking at the differences in the prevalence of alternative vehicles across different classes of GPs. Of course, their usage is likely to be a function of both their willingness to offer these alternatives, and the interest of asset owners in undertaking these investments.

Table 8 looks at the differences across private capital groups with various strategies (each group is assigned to only one strategy, based on where the bulk of its investment activity is focused). Following State Street's typology, we divide the groups into those focused on buyout,

\footnotetext{
${ }^{8}$ The presence of 112 LPs in Table 7 (as opposed to the 108 used elsewhere), reflects the fact that four asset owners in the sample had made no private equity commitments as of mid-2017.
} 
private debt, and venture capital transactions. We find a substantial disparity between venture capital-focused groups and the other classes. While $62 \%$ and $72 \%$ of the vehicles raised by buyoutand private debt-focused GPs were in main funds, $80 \%$ of those by venture capital-focused groups were. Similarly, the amount of capital raised by the venture-focused groups was much more concentrated in main funds, representing $90 \%$ of the total raised, as opposed to $82 \%$ and $83 \%$ for buyout- and private debt-focused groups.

Table 9 looks at the differences across general partners by size, dividing the groups into terciles based on total capital raised between 1980 and 2017. The smallest tercile of firms was far less likely to make use of alternative vehicles: these represented only $7 \%$ of the vehicles they offered and $2 \%$ of capital raised. The corresponding numbers for the largest tercile, by way of contrast, were $40 \%$ and $18 \%$.

In Table 10, similarly dramatic pattern appeared when we examined differences across geography of the GPs. In each case, we assign the group to the region in which its headquarters is located. North American-based GPs are far more likely to employ alternative vehicles: $33 \%$ of the vehicles and $17 \%$ of the capital raised were of this nature. Meanwhile, for groups outside of Europe and North America, alternative vehicles represented 21\% of the entities and $5 \%$ of the capital raised.

We then turn to examining the performance across different classes of GPs. We again examine unadjusted and adjusted excess PME performance, comparing that of the alternative vehicle and the paired main fund. Focusing on weighted average returns, we see in Table 11 that 
alternative vehicles of buyout-focused GPs had consistent negative returns compared to their paired main funds, regardless of the method of adjustment used. VC investments were similarly negative. Private debt strategies had more mixed results.

Tables 12 and 13 look similarly at the relationship of excess performance and fund size and GP geography. Again, focusing on the results using weighted-average returns, we find that the performance was poor, frequently at statistically significant levels, for vehicles raised by the largest tercile of firms (with adjusted PME differences of -0.018 and -0.104 for discretionary and GP-managed vehicles) and managers based in North America (-0.070 and -0.132 respectively). The effects were again most negative for GP-directed funds.

\section{B. Multiple Regression Analysis}

Tables 14 looks at the differences in the use of alternative vehicles across GPs of different types in regression analyses. (The definition of all independent variables is in Appendix A.) We use as observations each private equity group that raised funds in a given five-year period (from 1980 to 1984,1985 to 1989 , and so forth). If the private equity raised multiple five-year periods, there are multiple observations; if the group raised no funds in a five-year period, the period is not used as an observation. In each table, we present the results weighted and unweighted by the size of the capital raised by the private equity group in the given five-year period. We also ran the regressions with and without the performance of earlier funds raised by the GP in the previous five year period as independent variables. While this variable is of interest, because some firms did not raise funds during the period, the sample size shrinks. 
Table 14 examines the share of the funds raised by each general partner. The dependent variable in the first six regressions is the ratio of discretionary and GP-directed vehicle commitments to total capital commitments in each five-year period for each GP. This variable measures how GPs raise funds across main funds and alternative vehicles. We regress this variable on GP characteristics; in particular fund size, fund strategy, the region the GP operates in, and the performance of the partnership in the five prior years.

The regressions show that in the more recent period, alternative vehicles as a share of total fundraising has increased. We interact the time trend $(\mathrm{T})$ with dummies for fund size terciles and find that over time the largest groups appear to be more likely to offer these vehicles. We also see that VC funds and debt funds have become less likely to employ alternative vehicles relative to buyout funds. When we break out these patterns by GP-directed versus discretionary funds, we see that the effects are primarily driven by the former funds. Finally, we look at the fundraising pattern in relation to past performance of the partnership. We find a strong negative relationship between the ratio of fund raising via alternative vehicles and a partnership's past performance. We again differentiate between GP-directed versus discretionary vehicles and find that the relationship is statistically stronger for the discretionary vehicles, but that the coefficients are of a similar magnitude across both groups. Top-performing funds appear to raise a smaller share of their overall funds via alternative vehicles. However, when we look at the absolute volume of funds raised via alternative vehicles in the last column, we see that the sign flips. Better performing partnerships increase their fund raising in alternative vehicles. But as a share of their total fund raising, alternative vehicles become smaller, which implies that the better performing partnerships are able to grow their main funds even more quickly. 
Table 15 looks at the performance of funds, using Adjusted Excess PME Performance as the dependent variable. Each alternative vehicle is an observation. In Panel A, we look at the adjusted excess PME performance, i.e., the performance of alternative vehicles relative to their main fund. Three patterns stand out. The first is that the relative performance of discretionary vehicles is significantly lower than the GP-directed vehicles. The performance difference was less evident in the univariate comparison, where we did not control for the time trend and fund type. The second finding is that alternative investments offered by general partners in the rest of the world significantly outperformed in the early years, though this advantage seems to fade over time. Finally, there is a negative relationship between a partnership's five-year prior performance and the performance of its alternative vehicles (relative to their main fund). The results are not significant in the full sample. But when we examine GP-directed and discretionary funds separately, we see a stark asymmetry. GP-directed vehicles offered by groups with historically high PMEs have lower relative performance compared to those offered by groups with lower PME. In contrast, discretionary funds offered by groups with better past performance also performed better, but the relationship is only marginally significant.

These patterns are provocative and seem to support our story of bargaining between GPs and LPs. As discussed above, there are two channels which could explain that lower performance: The first is that high-performing groups may exploit their market power by offering alternative vehicles with less favorable economics. Another possibility is that these GPs have higher levels of performance in their main funds, but since they only have limited access to proprietary top deals, the quality of assets in the alternative vehicles is lower. It is important to note that these vehicles 
might still provide very reasonable returns to investors who are not able to invest in the very top partnerships.

To test this question about the absolute performance of the alternative vehicles, Panel B looks at the raw PMEs (that is, with no adjustment for the performance of proximate main funds) of each alternative vehicle. We find that top-performing groups are more likely to have high performing alternative vehicles when we look at raw performance. In the univariate statistics above, we saw that on average alternative vehicles perform as well as the market. This suggests that better performing GPs offer alternative vehicles which perform worse than their main funds, but still offer investors a return that is commensurate with the rest of the market.

We also see that discretionary vehicles perform worse on average, but this difference weakens over time. But in both specifications, we find that funds with better past performance offer discretionary vehicles that perform better and even outperform the main fund of the partnership. This result seems surprising if GPs have market power as we argued before. However, it might be the result of assortative matching, where better GPs are more likely to be matched with more powerful LPs, which might demand co-investment opportunities. To test these ideas we will now turn to looking at the interaction between LPs and GPs.

\section{Patterns across Limited Partners}

We then look at the patterns across different classes of limited partners in their usage of alternative vehicles. As has been documented in the finance literature (Lerner, Schoar, and 
Wongsunwai, 2007; Sensoy, Wang, and Weisbach, 2014), investment decisions regarding and the performance of private capital investments varied across classes of LPs (though in ways that may have varied over time). These considerations may also have affected the interest in alternative vehicles by different classes of limited partners. Of course, their usage of alternative vehicles was also likely to be a function of the willingness of general partners to offer them opportunities to invest in alternative vehicles.

Table 16 looks at the differences across classes of limited partners. We see substantial variations across the different investor types. The most striking pattern related to the share of the total capital devoted to alternative vehicles, where public pensions stand out. While their $\$ 31$ billion of commitments to alternative vehicles was the largest of any class of investor, they had so much committed to traditional funds that their $12 \%$ share of commitments was considerably smaller than every other class of investor, such as sovereign wealth funds, endowments and foundations, and private pensions.

Tables 17 and 18 look at the use of these vehicles across limited partners of different sizes and geographies. There were relatively few patterns in regard to size and the share of vehicles that were alternative ones. When it comes to the share of capital committed to such vehicles, smaller LPs were more active users of alternative vehicles. Turning to differences in the location of the LPs, there are few differences in the count of vehicles invested in. When we turn to capital deployment, LPs based outside of Europe and the North America (22\% of total capital), and especially European ones (28\%), made far more use of alternative vehicles than the North American asset owners (14\%). 
The next three tables look at the performance of the alternative vehicle investments by limited partner type. In Table 19, we see that funds-of-funds (FoF) had consistently negative relative performance across all three measures, with weighted average adjusted PME differences of -0.144 and -0.106 for discretionary and GP-managed vehicles (both statistically significant). Continuing to focus on weighted average relative returns, the alternative investments of public pensions were also consistent underperformers ( -0.083 and -0.065 respectively), though they look better when we examine medians. Insurance and finance institutions, in contrast did quite well in their alternative investments, with adjusted excess PMEs of 0.177 and 0.013 for discretionary and GP-directed vehicles, respectively. And finally, SWF did quite poorly on GP-directed investments $(-0.213)$ but moderately well on the discretionary vehicles $(0.082)$. When we look across LPs of different sizes in Table 20, we see that for the top tercile of largest funds, performance of GPdirected funds is significantly lower than the main fund (-0.094), while the difference in performance of discretionary funds to the main fund is close to zero (0.011)

In Table 21, we examine the differences across LPs with different geographic bases. We see a disparity, with those funds based in North America consistently underperforming in their alternative vehicle investments: their weighted average adjusted PME differences are -0.041 for both discretionary and GP-managed vehicles. Europe-based LPs did better in alternative vehicle investing $(+0.18$ and -0.02 respectively).

\section{Matching between LPS and GPS}


In Table 22, we first analyze which types of LPs do better in their alternative vehicle investments. Each investment by an individual LP in an alternative vehicle is an observation. The dependent variable is the vehicle's Adjusted Excess PME Performance. We include controls for the features of the LPs and GPs. We see the superior performance of insurers (which may have more experience in many instances with investments in alternative vehicles, as alluded to above), endowments and foundations (who have historically been skilled private market investors, as documented by Lerner, Schoar, and Wongsunwai, 2007)), and private pensions. LPs with historically high performance also do better in selecting alternative vehicles, which may suggest the persistence of skill effect (consistent with Cavagnaro, et al. 2017). Interestingly, LPs with historically high performance do better in both GP-directed and discretionary funds. This suggests that there is a group of LPs that has the skill to identify good co-investment vehicles but also does better with GP-directed funds.

Finally, Table 23 looks at the matching between GP and LP. Each investment by an individual LP in an alternative vehicle is an observation. The dependent variable is the vehicle's raw PME. We regress the performance of the alterative vehicle on a measure of the LP's and GP's performance in their entire portfolio, with controls for the GP size and strategy. In Columns 1, 3, and 5, we use the average performance over the total VCPE portfolio and the entire time period an LP or GP is in our sample. This is a time-invariant measure of LP and GP performance, which captures cross-sectional differences in performance. We then classify LPs into above median versus below median performers. We do the same for the GPs. We form four dummies to characterize the match between the LP and the GP: (1) LP and GP above median, (2) LP and GP below median, (3) LP above and GP below median, and (4) vice versa. In the even columns, we 
repeat the same regression set-up, but use as the performance measure the average volumeweighted PME in the five years prior to the inception of the alternative vehicle. We include GP fixed effects here, since this measure of performance varies over time.

The results show that the PME of an alternative vehicle where the LP and the GP are above median performers is 0.38 points higher than the base category of a below-median GP-LP pair. The dummies on the uneven matches is 0.18 points higher than the base category. All these differences are statistically significant. When breaking the results out by type of alternative vehicles, we find that the magnitudes of the results are larger for the discretionary vehicles, but the differences are also significant for the GP-directed vehicles. As discussed above, these results are in line with a bargaining explanation, where the top LPs receive better returns, even conditional on the performance of the GPs with which they invest.

\section{Conclusions}

Using hitherto-unexplored custodial data, we take a broad look at private capital investments by 108 LPs, including transactions involving assets outside the traditional fund structure. We show that alternative vehicles have been a major — and rapidly growing — portion of these investors' portfolios over the past four decades. We also document the disparity in the performance across the limited and general partners participating in such vehicles, as well as across the two broad classes of alternative vehicles.

Several avenues for future research follow naturally from this paper. One of these relates to the contractual terms in these "outside-the-box" investments. While the partnership agreements 
between GPs and LPs in main funds have been well scrutinized, we know very little about the nature of these alternative vehicle arrangements. In this analysis, as the earlier literature on coinvestments, we only observe the net cash flows to the LPs, not the payments that went to the GPs. Another intriguing question is whether the patterns seen here are replicated in other asset classes. One natural arena to investigate is real estate, where "blind pool" funds were far later in arriving than in private capital. Understanding how the use of such "outside the box" investments varies across asset classes, and the performance of such transactions, are important and interesting open questions. 


\section{References}

Admati, Anat, and Paul Pfleider, Robust financial contracting and the role of venture capitalists. Journal of Finance, 49, 1994, 371-402

Braun, Reiner, Tim Jenkinson, and Christoph Schemmerl, Adverse selection and the performance of private equity co-investments, Unpublished working paper, 2017, https://ssrn.com/abstract=2871458.

Brown, Gregory W., Robert S. Harris, Tim Jenkinson, Steven N. Kaplan, and David T. Robinson, What do different commercial data sets tell us about private equity performance?, Unpublished working paper, 2015, https://ssrn.com/abstract=2706556.

Cavagnaro, Daniel R., Berk A. Sensoy, Yingdi Wang, and Michael S. Weisbach, Measuring institutional investors' skill at making private equity investments, Journal of Finance, forthcoming, $\quad$ https://cpb-us-w2.wpmucdn.com/u.osu.edu/dist/8/7843/files/2017/10/CSWWOctober-2017-187cbq4.pdf.

The Clearing House, The Custody Services of Banks, Washington, The Clearing House, 2016, https://www.davispolk.com/files/20160728 tch_white_paper_the_custody_services_of_banks.pd f.

Cremers, Martijn, Miguel A. Ferreira, Pedro Matos, and Laura Starks, Indexing and active fund management: International evidence, Journal of Financial Economics, 120, 2016, 539-560.

Diamond, Douglas, Financial intermediation and delegated monitoring, Review of Economic Studies, 51, 1984, 393-414.

Fang, Lily, Victoria Ivashina, and Josh Lerner, The disintermediation of financial markets: Direct investing in private equity, Journal of Financial Economics, 116, 2015, 160-178.

Hardymon, G. Felda, Tom Nicholas, and Vasiliki Fouka, Venture capital at the Harvard Management Company in historical perspective, Harvard Business School case no. 9-815-047, 2014.

Harris, Robert S., Tim Jenkinson, and Steven N. Kaplan, How well do private equity investments perform relative to public equity?, Journal of Investment Management, 14 (3), 2016, 1-24.

Kaplan, Steven N., and Antoinette Schoar, Private equity performance: returns, persistence, and capital flows, Journal of Finance, 60, 2005, 1791-1823.

Khorana, Ajay, Henri Servaes, and Peter Tufano, Mutual fund fees around the world, Review of Financial Studies, 22, 2009, 1279-1310.

Leamon, Ann, Josh Lerner, and Vladimir Bosiljevac, Measurement, Governance, and Long-Term Investing, Geneva, World Economic Forum, 2012. 
Leland, Hayne E., and David H. Pyle, Informational asymmetries, financial structure, and financial intermediation, Journal of Finance, 32, 1977, 371-387.

Lerner, Josh, Matthew Rhodes-Kropf, and Nathaniel Burbank, Canadian Pension Plan Investment Board: October 2012, Harvard Business School case no. 9-813-103, 2013.

Lerner, Josh, and Antoinette Schoar, The illiquidity puzzle: Theory and evidence from private equity, Journal of Financial Economics, 72, 2004, 3-40.

Lerner, Josh, Antoinette Schoar, and Wan Wongsunwai, Smart institutions, foolish choices: The limited partner performance puzzle, Journal of Finance, 62, 2007, 731-764.

William M. Mercer, Key Terms and Conditions for Private Equity Investing, New York: William M. Mercer, 1996.

Metrick, Andrew, and Ayako Yasuda, Venture Capital and the Finance of Innovation, New York, Wiley, 2006.

Metrick, Andrew, and Ayako Yasuda, The economics of private equity funds, Review of Financial Studies, 23, 2010, 2303-2341.

Phalippou, Ludovic, Christian Rauch, and Marc P. Umber, Private equity portfolio company fees, Saïd Business School Working Paper no. 2015-22, 2016.

Preqin, Private Equity Co-Investment Outlook, London, Preqin, 2015.

Preqin, Preqin Global Private Equity and Venture Capital Report, London, Preqin, 2017.

Rhodes-Kropf, Matthew, Luis Viceira, John Dionne, and Nathaniel Burbank, Texas Teachers and the new Texas way, Harvard Business School case no. 9-214-091, 2014.

Robinson, David T., and Berk Sensoy, Do private equity fund managers earn their fees? Compensation, ownership, and cash flow performance, Review of Financial Studies, 26, 2013, 2760-97.

Sensoy, Berk, Yingdi Wang, and Michael Weisbach, Limited partner performance and the maturing of the private equity industry, Journal of Financial Economics, 112, 2014, 320-343. 
Figure 1: Vehicle Number by Vintage Year

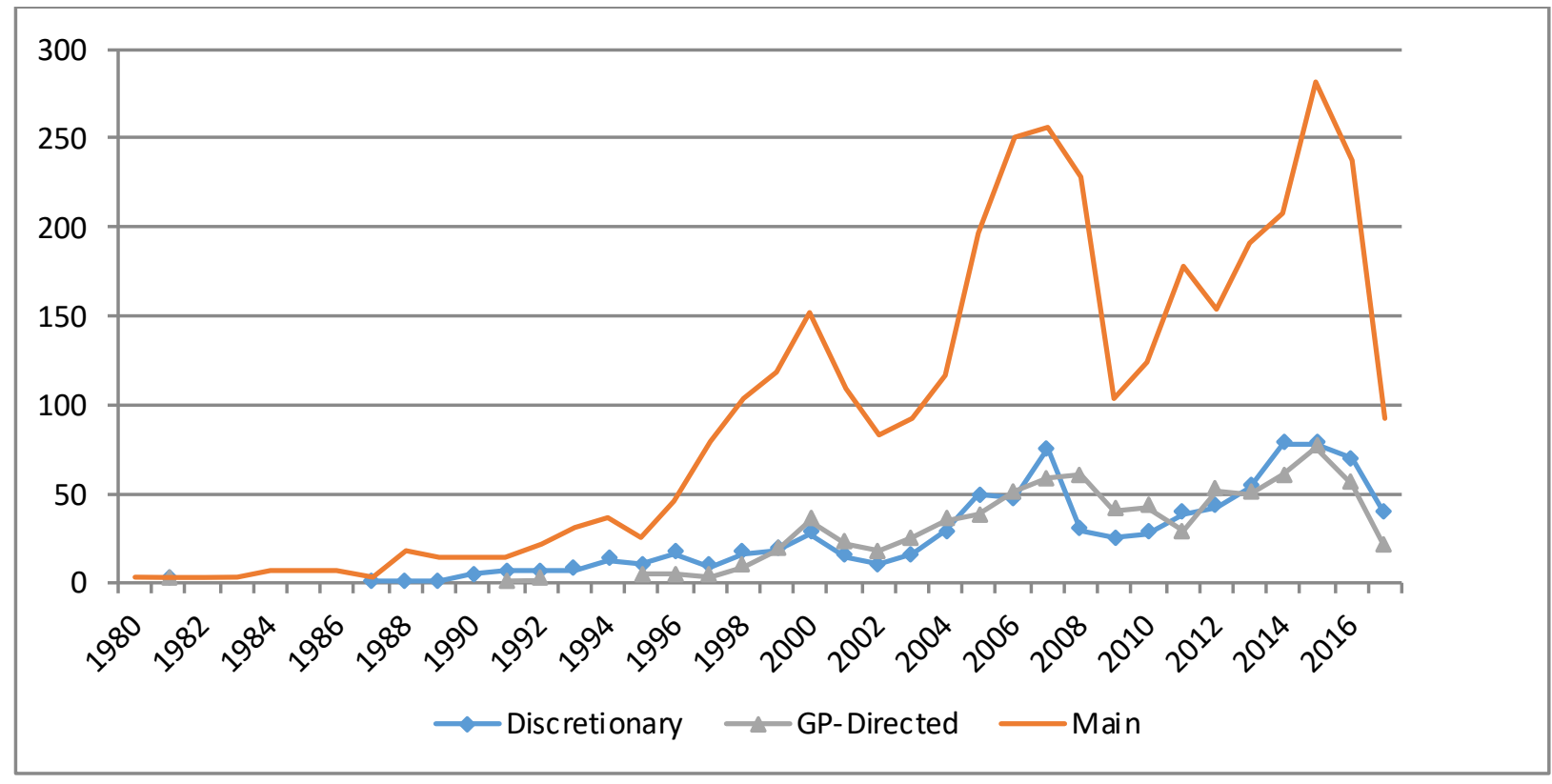

Figure 2: Vehicle Size (Commitments USD Millions) by Vintage Year

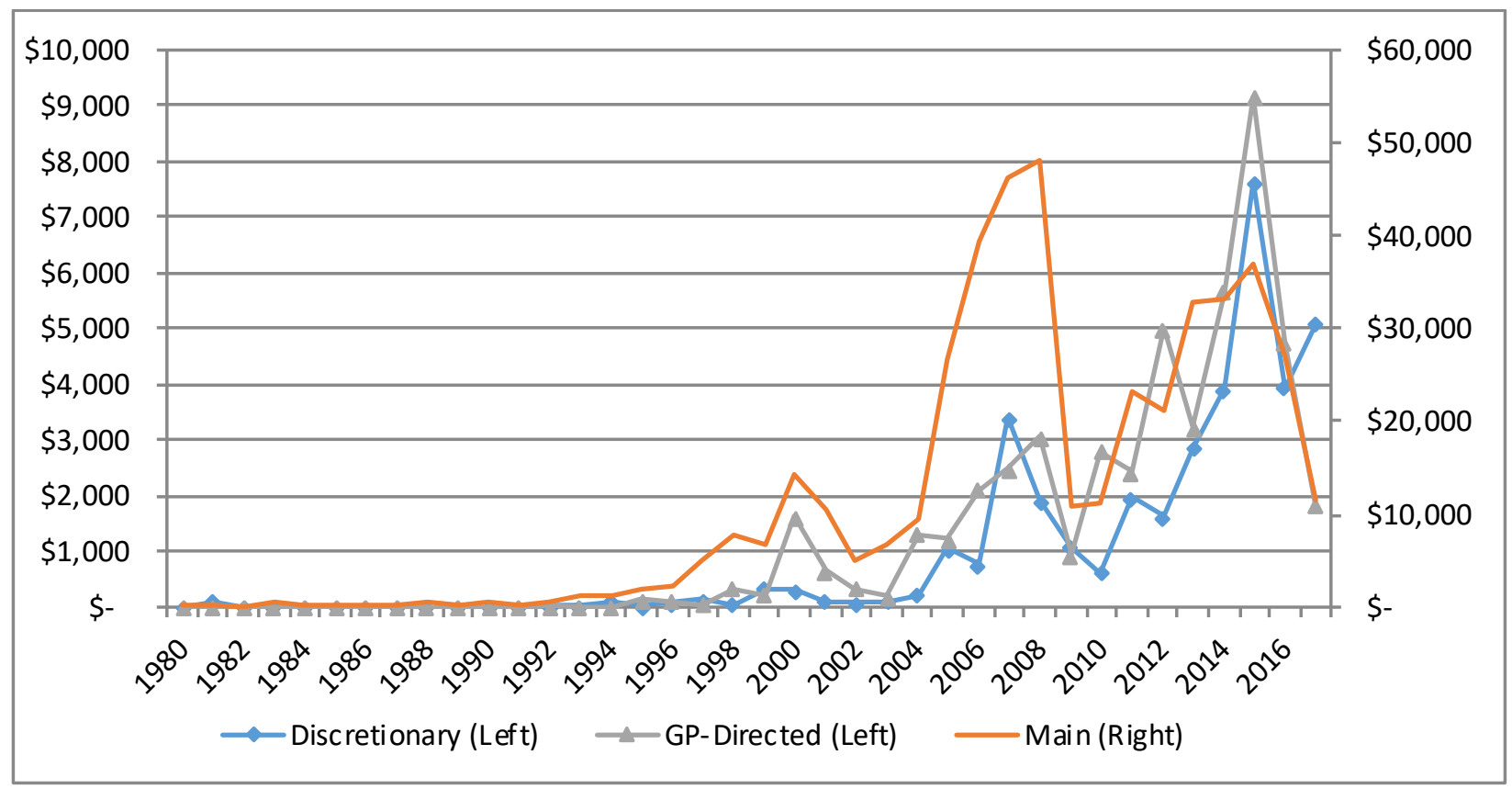


Figure 3: Median Performance by Vehicle Type and Vintage Year

Panel A. Median PME (relative to the Russell 3000) by fund type and vintage year.

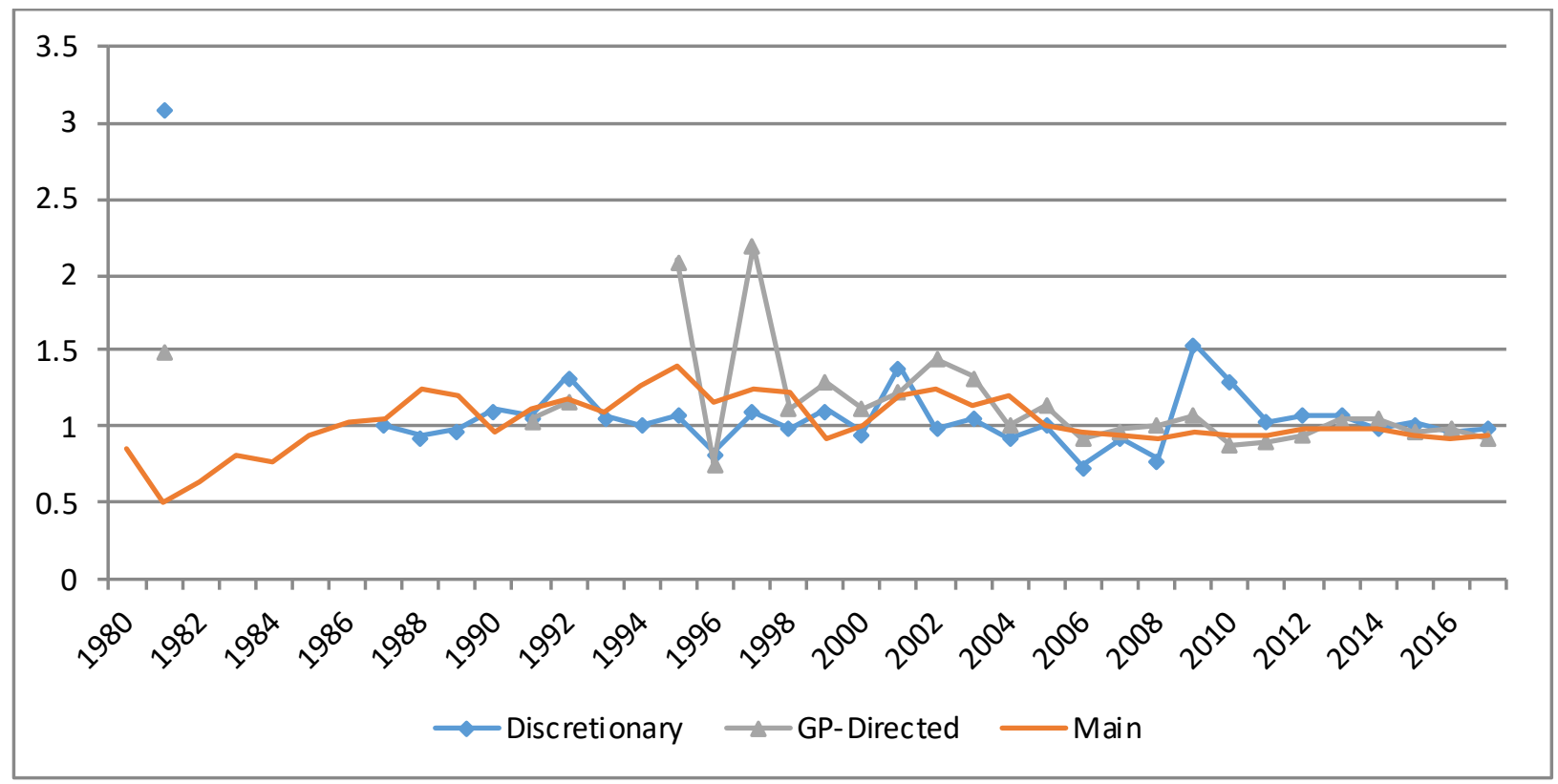

Panel B. Median IRR by fund type and vintage year.

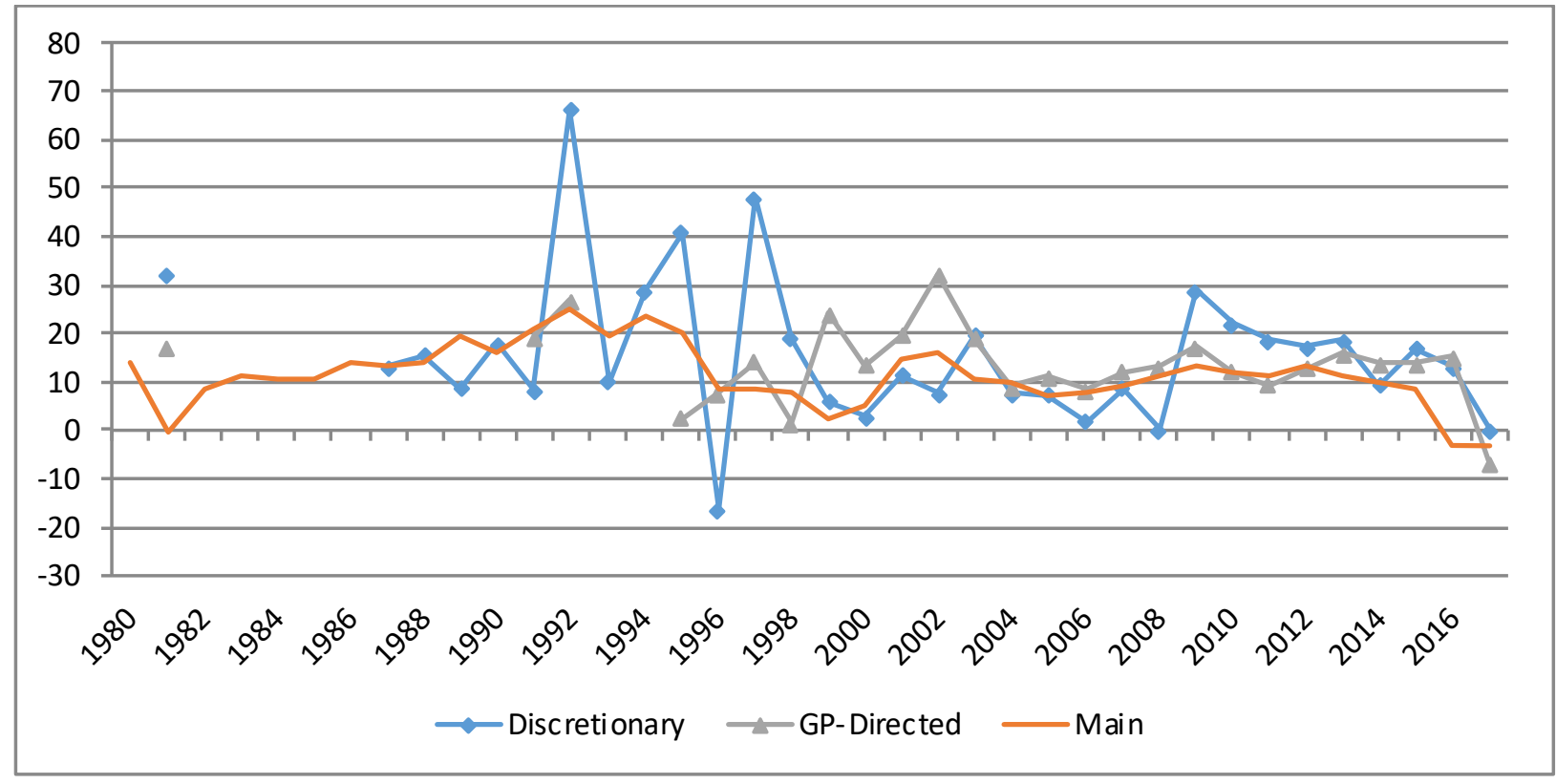


Panel C. Median TVPI by fund type and vintage year.

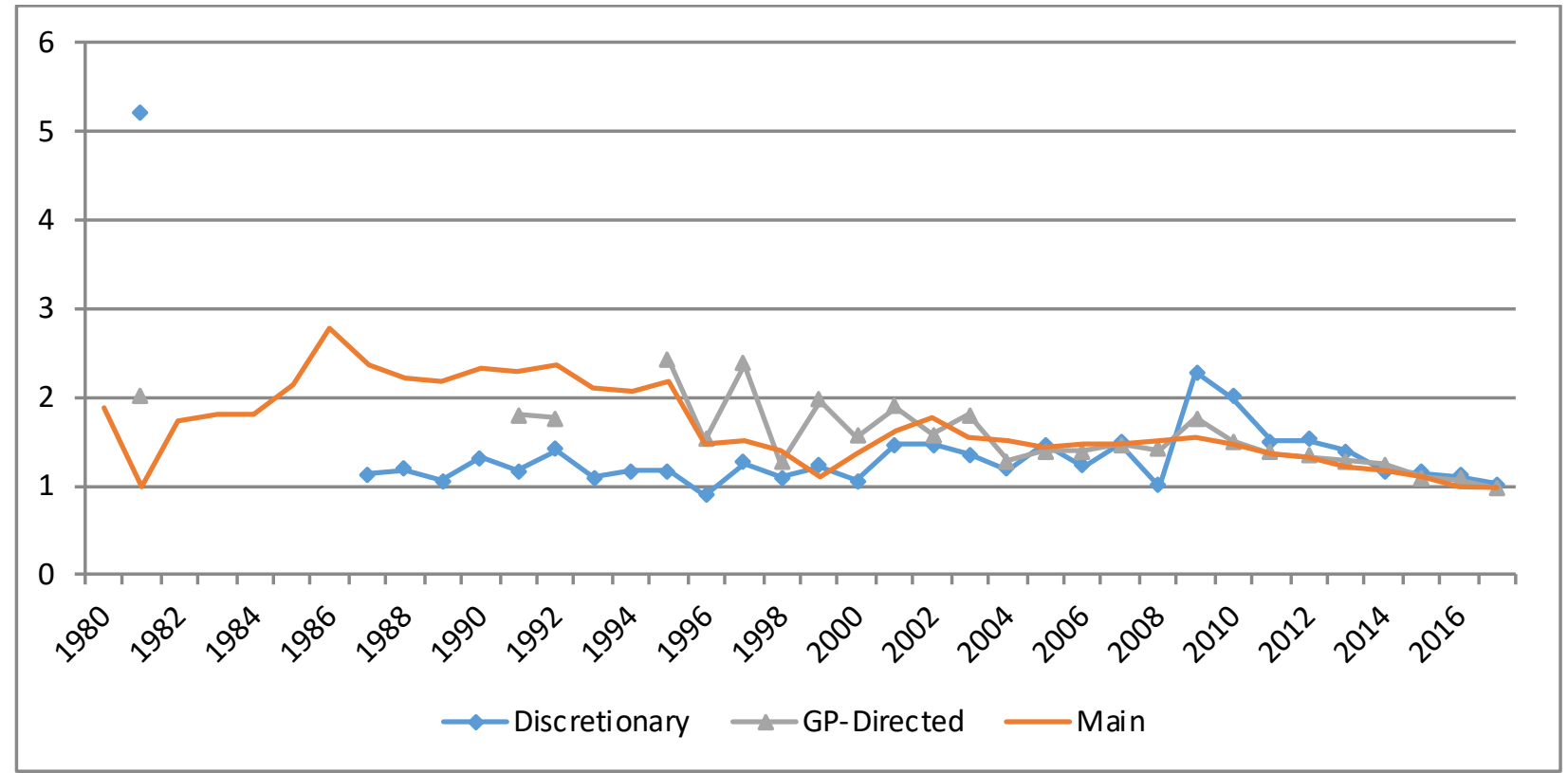


Figure 4: Excess Performance of Alternative Vehicles, by Vehicle Type. Excess PMEs are winsorized at the $0.5^{\text {th }}$ and $99.5^{\text {th }}$ percentiles.

Panel A. Histogram of Unadjusted Excess PME Performance of Discretionary Vehicles.

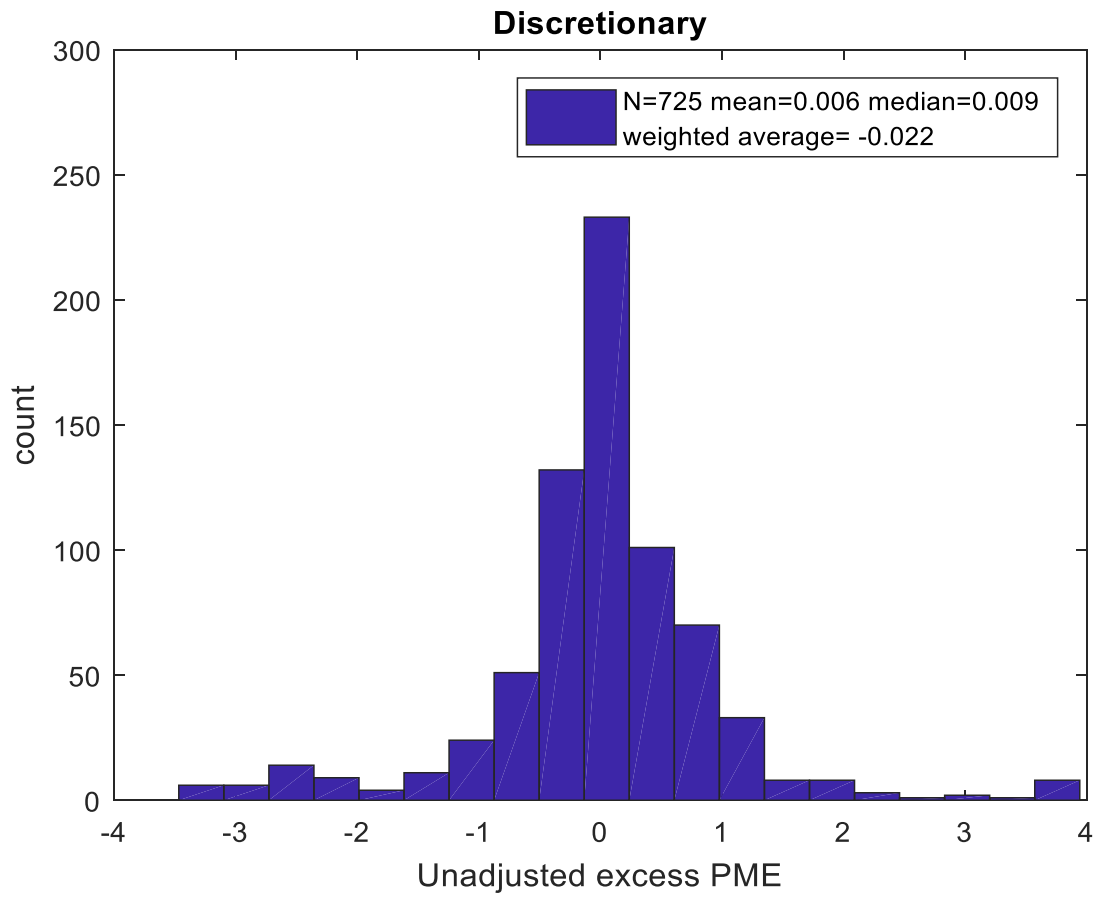

Panel B. Histogram of Adjusted Excess PME of Discretionary Vehicles.

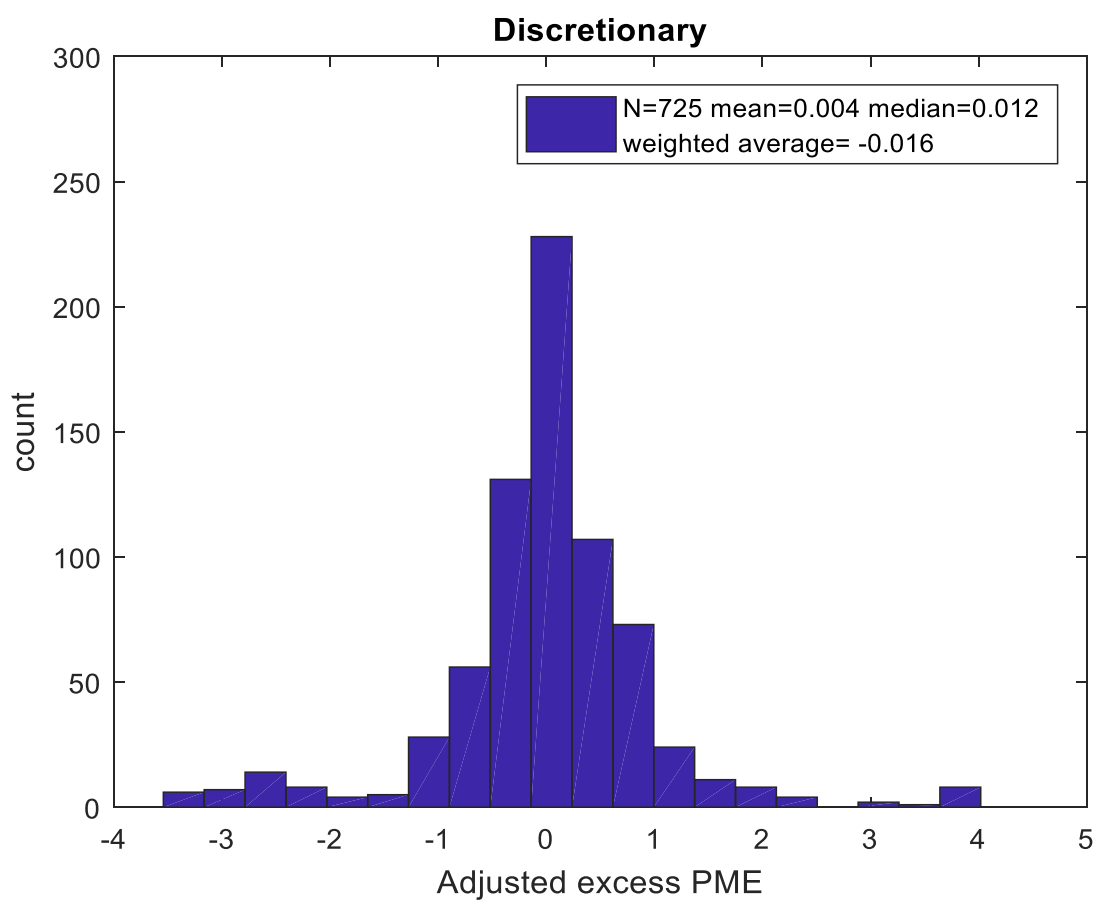


Panel C. Histogram of Unadjusted Excess PME Performance of GP-Directed Vehicles.

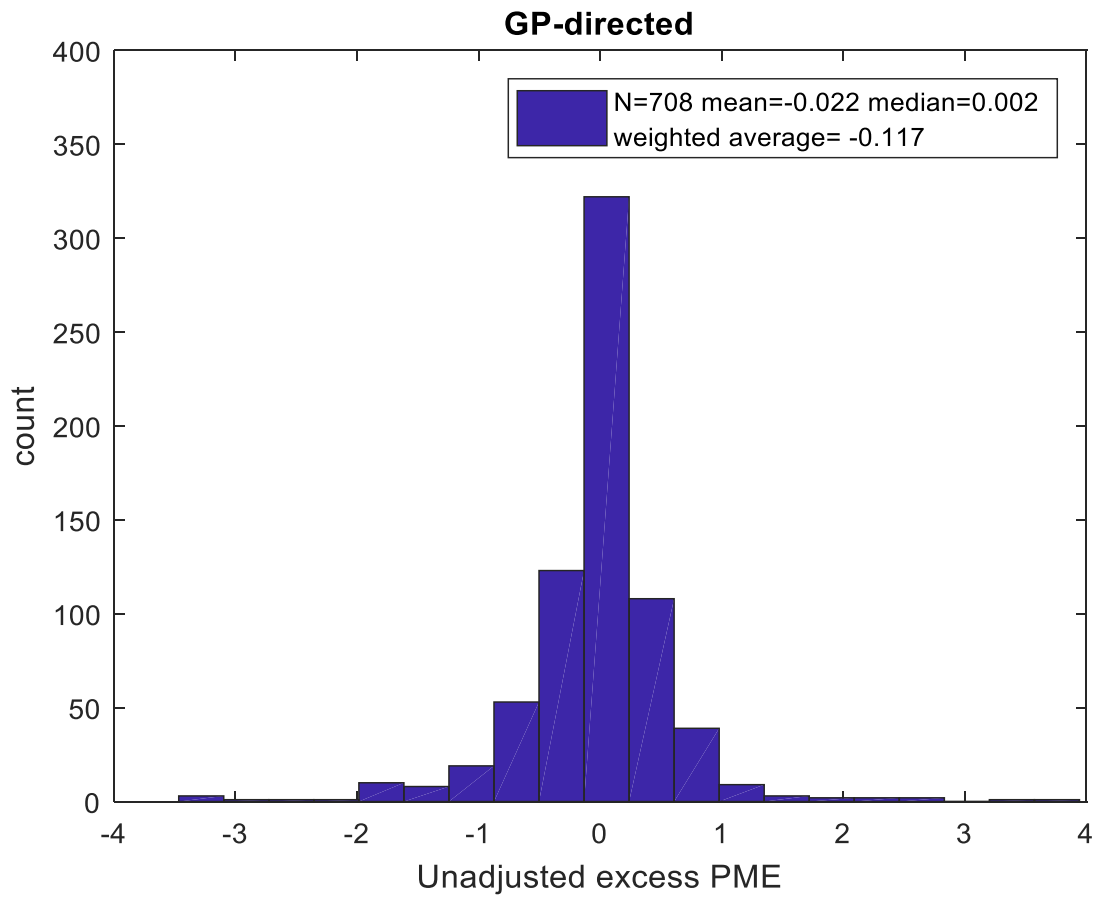

Panel D. Histogram of Adjusted Excess PME Performance of GP-Directed Vehicles.

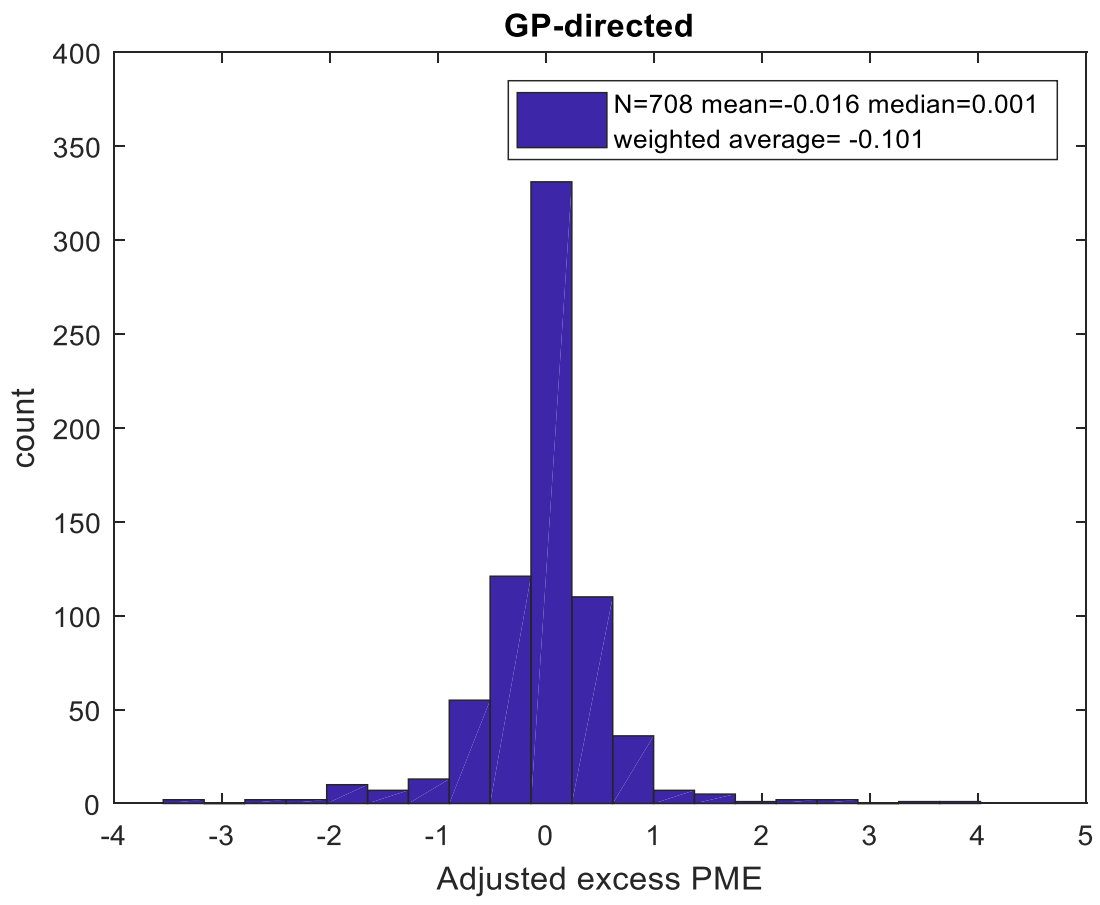


Table 1: Vehicle Count, Vehicle Investment Count, GP Count, LP Count, and Total and Average USD LP Commitment, by Vehicle Type.

\begin{tabular}{ccccccc}
\hline Vehicle type & $\begin{array}{c}\text { Vehicle } \\
\text { count }\end{array}$ & $\begin{array}{c}\text { Investment } \\
\text { count }\end{array}$ & $\begin{array}{c}\text { GP } \\
\text { count }\end{array}$ & $\begin{array}{c}\text { LP } \\
\text { count }\end{array}$ & $\begin{array}{c}\text { Total LP } \\
\text { Commitment } \\
\text { (USD MM) }\end{array}$ & $\begin{array}{c}\text { Average LP } \\
\text { commitment } \\
\text { (USD MM) }\end{array}$ \\
\hline Main & $\begin{array}{c}3,620 \\
(68.0 \%)\end{array}$ & $\begin{array}{c}15,553 \\
(78.7 \%)\end{array}$ & 868 & 108 & $\begin{array}{c}444,190 \\
(83.5 \%)\end{array}$ & 29 \\
Discretionary & 883 & 1,800 & \multirow{2}{*}{197} & 69 & $\begin{array}{c}37,874 \\
(7.1 \%)\end{array}$ & 21 \\
& $(16.6 \%)$ & $(9.1 \%)$ & & & $\begin{array}{l}49,848 \\
(9.4 \%)\end{array}$ & 21 \\
GP-Directed & 819 & 2,411 & 261 & 87 & & \\
\hline
\end{tabular}


Table 2: Breakdown of Vehicle Formation by Decade of Vehicle Vintage Year: Vehicle Count, Vehicle Investment Count, and Total USD Commitment, by Vehicle Type

Panel A: Counts by Vehicle Type and Decade of Vehicle Vintage Year.

\begin{tabular}{|c|c|c|c|c|}
\hline Vehicle type & $\begin{array}{r}\mathrm{VY} \\
\text { decade }\end{array}$ & $\begin{array}{r}\text { Vehicle } \\
\text { count }\end{array}$ & $\begin{array}{r}\text { Investment } \\
\text { count }\end{array}$ & $\begin{array}{r}\text { Total LP Commitment (USD } \\
\text { MM) }\end{array}$ \\
\hline Main & 1980 & 69 & 148 & 2,020 \\
\hline Main & 1990 & 491 & 1,376 & 27,200 \\
\hline Main & 2000 & 1,589 & 8,588 & 217,565 \\
\hline Main & 2010 & 1,470 & 5,440 & 197,350 \\
\hline $\begin{array}{c}\text { Discretionar } \\
\mathbf{y}\end{array}$ & 1980 & 5 & 5 & 118 \\
\hline $\begin{array}{c}\text { Discretionar } \\
\mathbf{y}\end{array}$ & 1990 & 109 & 113 & 789 \\
\hline $\begin{array}{c}\text { Discretionar } \\
\mathbf{y}\end{array}$ & 2000 & 324 & 835 & 9,034 \\
\hline $\begin{array}{c}\text { Discretionar } \\
\mathbf{y}\end{array}$ & 2010 & 429 & 826 & 27,642 \\
\hline GP-Directed & 1980 & 2 & 4 & 32 \\
\hline GP-Directed & 1990 & 45 & 125 & 885 \\
\hline GP-Directed & 2000 & 384 & 1,450 & 13,916 \\
\hline GP-Directed & 2010 & 386 & 830 & 34,855 \\
\hline
\end{tabular}

Panel B: Vehicle Type and Decade of Vehicle Vintage Year, as a Share of Total Activity.

\begin{tabular}{crrrr}
\hline Vehicle type & VY decade & \% Vehicles & \% Investments & \% Total Commitment \\
\hline Main & 1980 & $90.8 \%$ & $94.3 \%$ & $93.1 \%$ \\
Main & 1990 & $76.1 \%$ & $85.3 \%$ & $94.2 \%$ \\
Main & 2000 & $69.2 \%$ & $79.0 \%$ & $90.5 \%$ \\
Main & 2010 & $64.3 \%$ & $76.7 \%$ & $75.9 \%$ \\
Discretionary & 1980 & $6.6 \%$ & $3.2 \%$ & $5.4 \%$ \\
Discretionary & 1990 & $16.9 \%$ & $7.0 \%$ & $2.7 \%$ \\
Discretionary & 2000 & $14.1 \%$ & $7.7 \%$ & $3.8 \%$ \\
Discretionary & 2010 & $18.8 \%$ & $11.6 \%$ & $10.6 \%$ \\
GP-Directed & 1980 & $2.6 \%$ & $2.5 \%$ & $1.5 \%$ \\
GP-Directed & 1990 & $7.0 \%$ & $7.7 \%$ & $3.1 \%$ \\
GP-Directed & 2000 & $16.7 \%$ & $13.3 \%$ & $5.8 \%$ \\
GP-Directed & 2010 & $16.9 \%$ & $11.2 \%$ & $13.4 \%$ \\
\hline
\end{tabular}


Table 3: Performance by Vehicle Type. The performance metrics reported are Kaplan-Schoar Public Market Equivalent versus the Russell 3000, Internal Rate of Return, and Total Value divided by Paid-In Capital. Weighted averages are by vehicle's total commitment by limited partners in the sample. PME, IRR, and TVPI are winsorized at $99^{\text {th }}$ percentile.

\begin{tabular}{crrrrr}
\hline & \multicolumn{5}{c}{ Russell 3000 KS PME } \\
\hline Vehicle type & $\mathbf{N}$ & $\mathbf{2 5 \%}$ & $\mathbf{5 0 \%}$ & $\mathbf{7 5 \%}$ & Weighted Average \\
Main & 3562 & 1.23 & 0.97 & 0.77 & 1.02 \\
Main AV-Associated & 679 & 1.20 & 0.97 & 0.76 & 1.02 \\
Discretionary & 840 & 1.23 & 0.99 & 0.77 & 0.99 \\
GP-Directed & 799 & 1.24 & 1.01 & 0.81 & 0.97 \\
\hline & & & & & 0.09 \\
& & & IRR & & 0.10 \\
Vehicle type & $\mathbf{N}$ & $\mathbf{2 5 \%}$ & $\mathbf{5 0 \%}$ & $\mathbf{7 5 \%}$ & 0.09 \\
Main & 3562 & 0.17 & 0.09 & 0.00 & 0.11 \\
Main AV-Associated & 679 & 0.17 & 0.09 & 0.00 & \\
Discretionary & 840 & 0.24 & 0.10 & -0.01 & \\
GP-Directed & 799 & 0.22 & 0.12 & 0.03 & 1.37 \\
\hline & & & & & 1.37 \\
Vehicle type & & & $\mathbf{T V P I}$ & & 1.26 \\
Main & 3562 & 1.70 & 1.28 & 1.00 & 1.26 \\
Main AV-Associated & 679 & 1.66 & 1.22 & 1.00 & Weighted Average \\
Discretionary & 840 & 1.57 & 1.16 & 0.95 & 1.05 \\
GP-Directed & 799 & 1.70 & 1.32 & & \\
\hline
\end{tabular}

Table 4: Unadjusted Excess PME Performance of Alternative Vehicles. The performance of each alternative vehicle is compared to that of the main fund (or funds) raised by the same group of the same type in the past five years. The performance metric used is the Kaplan-Schoar Public Market Equivalent versus the Russell 3000. Weighted averages are computed using commitment size. Excess PMEs are winsorized at the $0.5^{\text {th }}$ and $99.5^{\text {th }}$ percentiles.

\begin{tabular}{ccccccc}
\hline Vehicle type & $\mathbf{N}$ & Weighted average & p-value & Average & p-value & median \\
\hline All & 1433 & -0.079 & 0.000 & -0.008 & 0.715 & 0.003 \\
Discretionary & 725 & -0.022 & 0.521 & 0.006 & 0.869 & 0.009 \\
GP-Directed & 708 & -0.117 & 0.000 & -0.022 & 0.343 & 0.002 \\
\hline
\end{tabular}


Table 5: Adjusted Excess PME Performance of Alternative Vehicles. The performance of each alternative vehicle is compared to that of the main fund (or funds) raised by the same group of the same type in the past five years, but where both funds are computed relative to the mean PME for main funds in the vintage of the vehicles formation. The performance metric used is the Kaplan-Schoar Public Market Equivalent versus the Russell 3000. Weighted averages are computed using commitment size. Excess PMEs are winsorized at the $0.5^{\text {th }}$ and $99.5^{\text {th }}$ percentiles.

\begin{tabular}{ccccccc}
\hline Vehicle type & $\mathbf{N}$ & Weighted average & p-value & Average & p-value & median \\
\hline All & 1433 & -0.066 & 0.001 & -0.006 & 0.795 & 0.004 \\
Discretionary & 725 & -0.016 & 0.657 & 0.004 & 0.912 & 0.012 \\
GP-Directed & 708 & -0.101 & 0.000 & -0.016 & 0.499 & 0.001 \\
\hline
\end{tabular}


Table 6: Excess Performance of Alternative Vehicles, by Decade of Vehicle Formation. The performance of each alternative vehicle is compared to that of the main fund (or funds) raised by the same group of the same type in the past five years. The performance metric used is the Kaplan-Schoar Public Market Equivalent versus the Russell 3000. Weighted averages are computed using commitment size. Excess PMEs are winsorized at the $0.5^{\text {th }}$ and $99.5^{\text {th }}$ percentiles.

Panel A. Unadjusted Excess PME Performance.

\begin{tabular}{ccrrrrrr}
\hline Vehicle type & Decade & $\mathbf{N}$ & Weighted average & p-value & Average & p-value & median \\
\hline All & $1990 \mathrm{~s}$ & 105 & -0.018 & 0.848 & -0.567 & 0.000 & -0.055 \\
All & $2000 \mathrm{~s}$ & 636 & -0.222 & 0.000 & 0.022 & 0.470 & 0.001 \\
All & $2010 \mathrm{~s}$ & 692 & -0.024 & 0.298 & 0.049 & 0.054 & 0.006 \\
Discretionary & $1990 \mathrm{~s}$ & 71 & -0.071 & 0.624 & -0.879 & 0.000 & -0.405 \\
Discretionary & $2000 \mathrm{~s}$ & 288 & -0.429 & 0.000 & 0.047 & 0.394 & -0.060 \\
Discretionary & $2010 \mathrm{~s}$ & 366 & 0.146 & 0.000 & 0.146 & 0.000 & 0.036 \\
GP-Directed & $1990 \mathrm{~s}$ & 34 & 0.032 & 0.777 & 0.087 & 0.605 & 0.007 \\
GP-Directed & $2000 \mathrm{~s}$ & 348 & -0.071 & 0.030 & 0.001 & 0.965 & 0.007 \\
GP-Directed & $2010 \mathrm{~s}$ & 326 & -0.138 & 0.000 & -0.058 & 0.076 & 0.000 \\
\hline
\end{tabular}

Panel B. Adjusted Excess PME Performance.

\begin{tabular}{crrrrrrr}
\hline Vehicle type & Decade & $\mathbf{N}$ & Weighted average & p-value & Average & p-value & median \\
\hline All & $1990 \mathrm{~s}$ & 105 & 0.010 & 0.918 & -0.564 & 0.000 & -0.007 \\
All & $2000 \mathrm{~s}$ & 636 & -0.206 & 0.000 & 0.022 & 0.475 & 0.000 \\
All & $2010 \mathrm{~s}$ & 692 & -0.014 & 0.558 & 0.054 & 0.038 & 0.009 \\
Discretionary & $1990 \mathrm{~s}$ & 71 & -0.049 & 0.750 & -0.900 & 0.000 & -0.405 \\
Discretionary & $2000 \mathrm{~s}$ & 288 & -0.419 & 0.000 & 0.047 & 0.395 & -0.042 \\
Discretionary & $2010 \mathrm{~s}$ & 366 & 0.151 & 0.000 & 0.146 & 0.000 & 0.046 \\
GP-Directed & $1990 \mathrm{~s}$ & 34 & 0.066 & 0.549 & 0.139 & 0.366 & 0.087 \\
GP-Directed & $2000 \mathrm{~s}$ & 348 & -0.049 & 0.127 & 0.001 & 0.977 & 0.005 \\
GP-Directed & $2010 \mathrm{~s}$ & 326 & -0.124 & 0.000 & -0.049 & 0.138 & 0.000 \\
\hline
\end{tabular}


Table 7: Characteristics of GPs and LPs.

\begin{tabular}{crrrrrr}
\hline GP & Count & Average & Median & $\begin{array}{r}\text { Standard } \\
\text { Deviation }\end{array}$ & $\mathbf{1 0 \%}$ & $\mathbf{9 0 \%}$ \\
\hline $\begin{array}{c}\text { 1st activity year } \\
\text { commitment (USD MM) }\end{array}$ & 870 & 2003.4 & 2005 & 7.96 & 2014 & 1993 \\
commitment \% & 870 & $\$ 611$ & $\$ 134$ & $\$ 2,065$ & $\$ 1,213$ & $\$ 15$ \\
\hline & & & $0.03 \%$ & $0.39 \%$ & $0.23 \%$ & $0.00 \%$ \\
\hline LP & Count & Average & Median & $\begin{array}{r}\text { Standard } \\
\text { Deviation }\end{array}$ & $\mathbf{1 0 \%}$ & $\mathbf{9 0 \%}$ \\
\hline $\begin{array}{c}\text { 1st activity year } \\
\text { commitment (USD }\end{array}$ & 112 & 1998.36 & 1999 & 9.32 & 2010 & 1983 \\
$\begin{array}{c}\text { MM) } \\
\text { commitment\% }\end{array}$ & 112 & $\$ 4,749$ & $\$ 775$ & $\$ 11,308$ & $\$ 12,106$ & $\$ 43$ \\
\hline & 112 & $0.89 \%$ & $0.15 \%$ & $2.13 \%$ & $2.28 \%$ & $0.01 \%$ \\
\hline
\end{tabular}

Table 8: Breakdown of Vehicle Formation by GP Strategy.

Panel A. Vehicle counts by GP strategy and vehicle structure.

\begin{tabular}{crrrr}
\hline Vehicle type & Buyout & $\begin{array}{r}\text { Private } \\
\text { Debt }\end{array}$ & Venture Capital & Grand Total \\
\hline Main & $2008(37.7 \%)$ & $443(8.3 \%)$ & $1169(22.0 \%)$ & $3620(68.0 \%)$ \\
Discretionary & $671(12.6 \%)$ & $73(1.4 \%)$ & $139(2.6 \%)$ & $883(16.6 \%)$ \\
GP-Directed & $564(10.6 \%)$ & $98(1.8 \%)$ & $157(3.0 \%)$ & $819(15.4 \%)$ \\
Grand Total & $3243(60.9 \%)$ & $614(11.5 \%)$ & $1465(27.5 \%)$ & 5322 \\
& & & & $(100.0 \%)$ \\
\hline
\end{tabular}

Panel B. USD commitment (millions) amount by GP strategy and vehicle structure.

\begin{tabular}{crrrr}
\hline Vehicle type & Buyout & Private Debt & Venture Capital & Grand Total \\
\hline Main & $\$ 333,084(62.6 \%)$ & $\$ 57,231(10.8 \%)$ & $\$ 53,875(10.1 \%)$ & $\$ 444,190(83.5 \%)$ \\
Discretionary & $\$ 30,140(5.7 \%)$ & $\$ 5,657(1.1 \%)$ & $\$ 2,077(0.4 \%)$ & $\$ 37,874(7.1 \%)$ \\
GP-Directed & $\$ 40,379(7.6 \%)$ & $\$ 5,669(1.1 \%)$ & $\$ 3,800(0.7 \%)$ & $\$ 49,848(9.4 \%)$ \\
Grand Total & $\$ 403,603(75.9 \%)$ & $\$ 68,557(12.9 \%)$ & $\$ 59,752(11.2 \%)$ & $\$ 531,912(100.0 \%)$ \\
\hline
\end{tabular}


Table 9: Breakdown of Vehicle Formation by GP Size. GPs are divided into terciles by the amount of capital they raised between 1980 and 2017. The top tercile has largest GP size.

Panel A. Vehicle counts by GP size tercile.

\begin{tabular}{crrrr}
\hline \multicolumn{5}{c}{ GP size tercile } \\
\hline Vehicle type & Bottom & Middle & Top & Grand Total \\
Main & $456(8.6 \%)$ & $902(16.9 \%)$ & $2262(42.5 \%)$ & $3620(68.0 \%)$ \\
Discretionary & $17(0.3 \%)$ & $64(1.2 \%)$ & $802(15.1 \%)$ & $883(16.6 \%)$ \\
GP-Directed & $14(0.3 \%)$ & $124(2.3 \%)$ & $681(12.8 \%)$ & $819(15.4 \%)$ \\
Grand Total & $487(9.2 \%)$ & $1090(20.5 \%)$ & $3745(70.4 \%)$ & $5322(100.0 \%)$ \\
\hline
\end{tabular}

Panel B. USD commitment (Millions) amount by GP size tercile.

\begin{tabular}{crcrr}
\hline & \multicolumn{5}{c}{ GP size tercile } \\
\hline Vehicle type & Bottom & Middle & Top & Grand Total \\
Main & $\$ 8,074$ & $\$ 37,437$ & $\$ 398,679$ & $\$ 444,190$ \\
& $(1.52 \%)$ & $(7.04 \%)$ & $(74.95 \%)$ & $(83.51 \%)$ \\
Discretionary & $\$ 43$ & $\$ 709$ & $\$ 37,122$ & $\$ 37,874$ \\
& $(0.01 \%)$ & $(0.13 \%)$ & $(6.98 \%)$ & $(7.12 \%)$ \\
GP-Directed & $\$ 92$ & $\$ 1,380$ & $\$ 48,376$ & $\$ 49,848$ \\
& $(0.02 \%)$ & $(0.26 \%)$ & $(9.09 \%)$ & $(9.37 \%)$ \\
Grand Total & $\$ 8,209$ & $\$ 39,526$ & $\$ 484,177$ & $\$ 531,912$ \\
& $(1.54 \%)$ & $(7.43 \%)$ & $(91.03 \%)$ & $(100.00 \%)$ \\
\hline
\end{tabular}

Table 10: Breakdown of Vehicle Formation by GP Geography.

Panel A. Investment counts by GP Geography and vehicle structure

\begin{tabular}{crrrr}
\hline Vehicle type & Europe & NA & RoW & Grand Total \\
\hline Main & $541(10.2 \%)$ & $2858(53.7 \%)$ & $221(4.2 \%)$ & $3620(68.0 \%)$ \\
Discretionary & $89(1.7 \%)$ & $778(14.6 \%)$ & $16(0.3 \%)$ & $883(16.6 \%)$ \\
GP-Directed & $156(2.9 \%)$ & $621(11.7 \%)$ & $42(0.8 \%)$ & $819(15.4 \%)$ \\
Grand Total & $786(14.8 \%)$ & $4257(80.0 \%)$ & $279(5.2 \%)$ & $5322(100.0 \%)$ \\
\hline
\end{tabular}

Panel B. USD commitment (Millions) amount by GP Geography and vehicle structure

\begin{tabular}{crrrr}
\hline Vehicle type & Europe & NA & RoW & Grand Total \\
\hline Main & $\$ 58,238$ & $\$ 367,828$ & $\$ 18,125$ & $\$ 444,191$ \\
& $(10.9 \%)$ & $(69.1 \%)$ & $(3.4 \%)$ & $(83.5 \%)$ \\
Discretionary & $\$ 4,067$ & $\$ 33,167$ & $\$ 640$ & $\$ 37,874$ \\
& $(0.8 \%)$ & $(6.2 \%)$ & $(0.1 \%)$ & $(7.1 \%)$ \\
GP-Directed & $\$ 7,825$ & $\$ 41,267$ & $\$ 756$ & $\$ 49,848$ \\
& $(1.5 \%)$ & $(7.8 \%)$ & $(0.1 \%)$ & $(9.4 \%)$ \\
Grand Total & $\$ 70,130$ & $\$ 442,262$ & $\$ 19,521$ & $\$ 531,913$ \\
& $(13.2 \%)$ & $(83.1 \%)$ & $(3.7 \%)$ & $(100.00 \%)$ \\
\hline
\end{tabular}


Table 11: Adjusted Excess Performance of Alternative Vehicles by GP Strategy. The performance of each alternative vehicle is compared that of the main fund (or funds) raised by the same group of the same type in the past five years. The performance metric used is the Kaplan-Schoar Public Market Equivalent versus the Russell 3000. Weighted averages are computed using commitment size. Excess PMEs are winsorized at the $0.5^{\text {th }}$ and $99.5^{\text {th }}$ percentiles.

\begin{tabular}{clrrrrrr}
\hline GP Strategy & Vehicle type & $\mathbf{N}$ & $\begin{array}{r}\text { Weighted } \\
\text { average }\end{array}$ & p-Value & Average & p-Value & Median \\
\hline Buyout & Discretionary & 559 & -0.045 & 0.294 & -0.029 & 0.513 & 0.009 \\
Buyout & GP-Directed & 499 & -0.102 & 0.000 & -0.003 & 0.911 & 0.007 \\
Private Debt & Discretionary & 51 & 0.235 & 0.005 & 0.249 & 0.007 & 0.137 \\
Private Debt & GP-Directed & 76 & -0.109 & 0.081 & -0.029 & 0.715 & 0.002 \\
$\quad \begin{array}{l}\text { Venture } \\
\text { Capital }\end{array}$ & Discretionary & 115 & -0.107 & 0.047 & 0.057 & 0.424 & 0.000 \\
$\quad$ Venture & GP-Directed & 133 & -0.059 & 0.083 & -0.055 & 0.303 & -0.006 \\
Capital & & & & & & & \\
\hline
\end{tabular}

Table 12: Adjusted Excess Performance of Alternative Vehicles by GP Size. The performance of each alternative vehicle is compared that of the main fund (or funds) raised by the same group of the same type in the past five years. The performance metric used is the Kaplan-Schoar Public Market Equivalent versus the Russell 3000. Weighted averages are computed using commitment size. GPs are divided into terciles by the amount of capital they raised between 1980 and 2017. Excess PMEs are winsorized at the $0.5^{\text {th }}$ and $99.5^{\text {th }}$ percentiles.

\begin{tabular}{clrrrrrr}
\hline GP Size & Vehicle type & $\mathbf{N}$ & Weighted average & p-Value & Average & p-Value & Median \\
\hline Bottom & Discretionary & 7 & 0.232 & 0.567 & 0.353 & 0.688 & 0.099 \\
Bottom & GP-Directed & 8 & -0.054 & 0.688 & -0.065 & 0.731 & -0.094 \\
Middle & Discretionary & 51 & 0.102 & 0.397 & 0.331 & 0.035 & 0.011 \\
Middle & GP-Directed & 96 & 0.032 & 0.398 & -0.031 & 0.553 & 0.001 \\
Top & Discretionary & 667 & -0.018 & 0.619 & -0.025 & 0.507 & 0.009 \\
Top & GP-Directed & 604 & -0.104 & 0.000 & -0.013 & 0.624 & 0.003 \\
\hline
\end{tabular}


Table 13: Adjusted Excess Performance of Alternative Vehicles by GP Geography. The performance of each alternative vehicle is compared that of the main fund (or funds) raised by the same group of the same type in the past five years. The performance metric used is the Kaplan-Schoar Public Market Equivalent versus the Russell 3000. Weighted averages are computed using commitment size. NA (i.e. North America) includes US and Canada. Excess PMEs are winsorized at the $0.5^{\text {th }}$ and $99.5^{\text {th }}$ percentiles.

\begin{tabular}{clrrrrrr}
\hline GP Region & Vehicle type & \multicolumn{1}{c}{$\mathbf{N}$} & Weighted average & p-Value & Average & p-Value & Median \\
\hline NA & Discretionary & 637 & -0.070 & 0.051 & -0.016 & 0.690 & 0.004 \\
NA & GP-Directed & 547 & -0.132 & 0.000 & -0.038 & 0.158 & 0.001 \\
Europe & Discretionary & 73 & 0.436 & 0.003 & 0.184 & 0.149 & 0.105 \\
Europe & GP-Directed & 127 & 0.077 & 0.057 & 0.086 & 0.092 & 0.007 \\
RoW & Discretionary & 15 & -0.077 & 0.573 & -0.040 & 0.823 & 0.002 \\
RoW & GP-Directed & 34 & -0.154 & 0.023 & -0.032 & 0.672 & -0.025 \\
\hline
\end{tabular}


Table 14. Analysis of Alternative Vehicle Activity by GP Characteristics. The dependent variable in the first six columns is the ratio of discretionary and GP-directed vehicle commitments to total capital commitments in each five-year period for each GP. The dependent variable in last column is the $\log 10$ of $1+$ alternative vehicle commitment in each five-year period for each GP. Weighted regressions use the sum of the GPs' capital commitments in the current five-year period as weights. GP prior five-year mean PME is an average over the previous five-year period, weighted by vehicle commitments. The reference categories are North America (US \& Canada) for GP region, buyout for GP strategy, and bottom tercile for GP size. Standard errors are clustered by GP and shown in parentheses. *, ** and *** denote statistical significance at the $10 \%, 5 \%$ and $1 \%$ level, respectively. $\mathrm{T}$ is a five year series time trend variable starting with 0 for $1980-84$.

\begin{tabular}{|c|c|c|c|c|c|c|c|}
\hline \multirow[b]{2}{*}{ Variables } & \multicolumn{4}{|c|}{ All alternative vehicles (ratio) } & \multirow{2}{*}{$\begin{array}{c}\begin{array}{c}\text { Discretionary } \\
\text { (ratio) }\end{array} \\
\text { Weighted }\end{array}$} & \multirow{2}{*}{$\begin{array}{c}\begin{array}{c}\text { GP-Directed } \\
\text { (ratio) }\end{array} \\
\text { Weighted }\end{array}$} & \multirow{2}{*}{$\begin{array}{c}\text { All } \\
\text { alternative } \\
\text { vehicles } \\
\text { (level) }\end{array}$} \\
\hline & Unweighted & Weighted & Unweighted & Weighted & & & \\
\hline \multirow[t]{2}{*}{ GP_region $_{\text {Europe }}$} & 0.160 & 0.173 & 0.192 & 0.261 & -0.044 & 0.305 & 0.745 \\
\hline & $(0.075)^{* *}$ & $(0.112)$ & $(0.088)^{* *}$ & $(0.131)^{* *}$ & $(0.116)$ & $(0.084)^{* * *}$ & $(1.901)$ \\
\hline \multirow[t]{2}{*}{$G P \_r e g i o n_{R o W}$} & 0.054 & 0.187 & -0.156 & 0.054 & -0.091 & 0.144 & 8.571 \\
\hline & $(0.076)$ & $(0.132)$ & $(0.168)$ & $(0.233)$ & $(0.173)$ & $(0.111)$ & $(5.713)$ \\
\hline \multirow[t]{2}{*}{$G P_{-}$strategy $y_{V C}$} & 0.010 & 0.321 & 0.002 & 0.190 & 0.069 & 0.120 & -2.129 \\
\hline & $(0.037)$ & $(0.110)^{* * *}$ & $(0.062)$ & $(0.098)^{*}$ & $(0.078)$ & $(0.063)^{*}$ & $(1.656)$ \\
\hline \multirow[t]{2}{*}{ GP_strategy $y_{\text {Debt }}$} & 0.014 & 0.263 & 0.024 & 0.370 & 0.207 & 0.163 & 4.783 \\
\hline & $(0.051)$ & $(0.116)^{* *}$ & $(0.104)$ & $(0.179)^{* *}$ & $(0.122)^{*}$ & $(0.082)^{* *}$ & $(4.030)$ \\
\hline \multirow[t]{2}{*}{ GP_size Middle } & -0.115 & -0.025 & -0.035 & 0.006 & 0.004 & 0.002 & 1.578 \\
\hline & $(0.032)^{* * *}$ & $(0.046)$ & $(0.067)$ & $(0.084)$ & $(0.052)$ & $(0.049)$ & $(1.806)$ \\
\hline \multirow[t]{2}{*}{ GP_size $_{\text {Top }}$} & -0.082 & -0.105 & -0.085 & -0.052 & -0.017 & -0.035 & 3.107 \\
\hline & $(0.036)^{* *}$ & $(0.074)$ & $(0.059)$ & $(0.076)$ & $(0.052)$ & $(0.047)$ & $(1.679)^{*}$ \\
\hline \multirow[t]{2}{*}{ GP_prior_5yr_PME } & & & -0.020 & -0.061 & -0.030 & -0.032 & 0.693 \\
\hline & & & $(0.009)^{* *}$ & $(0.027)^{* *}$ & $(0.014)^{* *}$ & $(0.019)$ & $(0.312)^{* *}$ \\
\hline \multirow[t]{2}{*}{$T$} & 0.004 & 0.044 & 0.020 & 0.060 & 0.026 & 0.034 & 0.392 \\
\hline & $(0.006)$ & $(0.013)^{* * *}$ & $(0.015)$ & $(0.018)^{* * *}$ & $(0.014)^{*}$ & $(0.012)^{* * *}$ & $(0.314)$ \\
\hline \multirow[t]{2}{*}{$T \times G P \_r e g i o n_{\text {Europe }}$} & -0.026 & -0.032 & -0.031 & -0.046 & 0.005 & -0.051 & -0.177 \\
\hline & $(0.014)^{*}$ & $(0.024)$ & $(0.017)^{*}$ & $(0.027)^{*}$ & $(0.024)$ & $(0.017)^{* * *}$ & $(0.305)$ \\
\hline \multirow[t]{2}{*}{$T \times G P \_r e g i o n_{R o W}$} & -0.019 & -0.050 & 0.010 & -0.033 & 0.005 & -0.038 & -1.679 \\
\hline & $(0.014)$ & $(0.024)^{* *}$ & $(0.031)$ & $(0.041)$ & $(0.030)$ & $(0.019)^{* *}$ & $(0.911)^{*}$ \\
\hline \multirow[t]{2}{*}{$T \times G P_{-}$strate $g y_{V C}$} & -0.004 & -0.067 & -0.005 & -0.049 & -0.018 & -0.031 & 0.015 \\
\hline & $(0.008)$ & $(0.019)^{* * *}$ & $(0.013)$ & $(0.020)^{* *}$ & $(0.015)$ & $(0.013)^{* *}$ & $(0.292)$ \\
\hline \multirow[t]{2}{*}{$T \times G P_{-}$strategy $y_{\text {Debt }}$} & -0.003 & -0.051 & -0.008 & -0.072 & -0.038 & -0.035 & -1.079 \\
\hline & $(0.011)$ & $(0.022)^{* *}$ & $(0.019)$ & $(0.029)^{* *}$ & $(0.020)^{*}$ & $(0.015)^{* *}$ & $(0.674)$ \\
\hline \multirow[t]{2}{*}{$T \times G P_{-}$size $_{\text {Middle }}$} & 0.033 & 0.013 & 0.020 & 0.004 & 0.003 & 0.002 & -0.028 \\
\hline & $(0.007)^{* * *}$ & $(0.009)$ & $(0.015)$ & $(0.017)$ & $(0.010)$ & $(0.010)$ & $(0.328)$ \\
\hline$T \times G P_{-}$size $_{\text {Top }}$ & 0.040 & 0.046 & 0.037 & 0.031 & 0.014 & 0.017 & 0.348 \\
\hline
\end{tabular}




\begin{tabular}{c|cccc|c|c|c} 
& $(0.007)^{* * *}$ & $(0.013)^{* * *}$ & $(0.013)^{* * *}$ & $(0.014)^{* *}$ & $(0.010)$ & $(0.009)^{*}$ & $(0.302)$ \\
\hline Observations & 2161 & 2161 & 1164 & 1164 & 1164 & 1164 & 1164 \\
Adjusted R-squared & 0.070 & 0.133 & 0.061 & 0.145 & 0.084 & 0.085 & 0.145 \\
\hline
\end{tabular}


Table 15. Regression Analyses of Alternative Vehicle Performance by GP Characteristics. Each alternative vehicle is an observation; the dependent variable is the Adjusted Excess PME Performance in Panel A and the PME performance in Panel B. Weighted regressions use the sum of the vehicles' capital commitments as weights. GP prior five-year mean PME is an average over the previous five years, weighted by vehicle commitments. The reference categories are North America (US \& Canada) for GP region, buyout for GP strategy, and bottom tercile for GP size. T is a time trend variable equal to vintage year less 1980 . Standard errors are clustered by GP and shown in parentheses. *, ** and *** denote statistical significance at the $10 \%, 5 \%$ and $1 \%$ level, respectively. Excess PMEs are winsorized at the $0.5^{\text {th }}$ and $99.5^{\text {th }}$ percentiles in Panel A; and at the $99^{\text {th }}$ percentile in Panel B.

Panel A. Adjusted Excess PME performance of alternative vehicle as dependent variable.

\begin{tabular}{|c|c|c|c|c|c|c|}
\hline \multirow[b]{2}{*}{ Variables } & \multicolumn{4}{|c|}{ All Alternative vehicles } & \multirow{2}{*}{$\begin{array}{c}\text { Discretionary } \\
\text { Weighted }\end{array}$} & \multirow{2}{*}{$\begin{array}{c}\text { GP-Directed } \\
\text { Weighted }\end{array}$} \\
\hline & Unweighted & Weighted & Unweighted & Weighted & & \\
\hline \multirow{2}{*}{ Vehicle_type $_{\text {Discretionary }}$} & -1.270 & -1.615 & -1.321 & -1.670 & & \\
\hline & $(0.561)^{* *}$ & $(1.189)$ & $(0.554)^{* *}$ & $(1.228)$ & & \\
\hline \multirow[t]{2}{*}{ GP_region $_{\text {Europe }}$} & 0.282 & -0.541 & 0.295 & -0.576 & -2.052 & 0.096 \\
\hline & $(0.588)$ & $(0.854)$ & $(0.591)$ & $(0.918)$ & $(1.778)$ & $(0.769)$ \\
\hline \multirow[t]{2}{*}{$G_{\text {_rregion }}$ Row } & 1.782 & 1.654 & 1.020 & 1.187 & 2.561 & -0.039 \\
\hline & $(0.693)^{* *}$ & $(0.825)^{* *}$ & $(0.736)$ & $(0.780)$ & $(1.306)^{* *}$ & $(1.211)$ \\
\hline \multirow[t]{2}{*}{$G P_{-}$strategy $y_{V C}$} & 0.946 & 0.161 & 1.142 & 0.326 & 2.355 & -0.896 \\
\hline & $(0.521)^{*}$ & $(0.720)$ & $(0.573)^{* *}$ & $(0.803)$ & $(1.697)$ & $(0.775)$ \\
\hline \multirow[t]{2}{*}{$G P \_s t r a t e g y_{D e b t}$} & 0.855 & 0.506 & 0.726 & 0.496 & 1.027 & -0.342 \\
\hline & $(0.567)$ & $(1.178)$ & $(0.594)$ & $(1.256)$ & $(1.811)$ & $(1.055)$ \\
\hline \multirow[t]{2}{*}{$G P_{-}$size $_{\text {Middle }}$} & 0.954 & -1.517 & 2.062 & -2.198 & -0.376 & 1.844 \\
\hline & $(2.022)$ & $(1.374)$ & $(3.090)$ & $(1.469)$ & $(1.619)$ & $(0.961)^{*}$ \\
\hline \multirow[t]{2}{*}{$G P_{-}$size $_{\text {Top }}$} & 1.496 & -2.300 & 3.131 & -2.628 & -2.553 & 2.015 \\
\hline & $(2.009)$ & $(1.318)^{*}$ & $(3.050)$ & $(1.484)^{*}$ & $(1.498)^{*}$ & $(1.069)^{*}$ \\
\hline \multirow[t]{2}{*}{$G P_{-}$prior $\_5 y r_{-} P M E$} & & & -0.067 & -0.031 & 0.643 & -0.297 \\
\hline & & & $(0.104)$ & $(0.180)$ & $(0.336)^{*}$ & $(0.139)^{* *}$ \\
\hline \multirow[t]{2}{*}{$T$} & 0.058 & -0.080 & 0.117 & -0.091 & -0.020 & 0.054 \\
\hline & $(0.071)$ & $(0.047)^{*}$ & $(0.103)$ & $(0.053)^{*}$ & $(0.058)$ & $(0.028)^{*}$ \\
\hline \multirow[t]{2}{*}{$T \times$ Vehicle_type $e_{\text {Discretionary }}$} & 0.046 & 0.054 & 0.048 & 0.055 & & \\
\hline & $(0.019)^{* *}$ & $(0.036)$ & $(0.019)^{* *}$ & $(0.037)$ & & \\
\hline \multirow[t]{2}{*}{$T \times G P \_$region $_{\text {Europe }}$} & -0.006 & 0.026 & -0.006 & 0.028 & 0.072 & 0.004 \\
\hline & $(0.020)$ & $(0.030)$ & $(0.020)$ & $(0.032)$ & $(0.059)$ & $(0.025)$ \\
\hline \multirow[t]{2}{*}{$T \times G P_{-}$region $_{\text {RoW }}$} & -0.060 & -0.054 & -0.037 & -0.040 & -0.080 & -0.002 \\
\hline & $(0.023)^{* * *}$ & $(0.025)^{* *}$ & $(0.024)$ & $(0.024)^{*}$ & $(0.039)^{* *}$ & $(0.038)$ \\
\hline \multirow[t]{2}{*}{$T \times G P \_$strategy $y_{V C}$} & -0.034 & -0.006 & -0.039 & -0.010 & -0.075 & 0.032 \\
\hline & $(0.018)^{*}$ & $(0.024)$ & $(0.019)^{* *}$ & $(0.026)$ & $(0.051)$ & $(0.027)$ \\
\hline \multirow[t]{2}{*}{$T \times G P_{-}$strategy $y_{\text {Debt }}$} & -0.027 & -0.012 & -0.023 & -0.012 & -0.023 & 0.011 \\
\hline & $(0.020)$ & $(0.036)$ & $(0.020)$ & $(0.039)$ & $(0.057)$ & $(0.033)$ \\
\hline$T \times G P_{-}$size $_{\text {Middle }}$ & -0.035 & 0.050 & -0.078 & 0.070 & 0.011 & -0.062 \\
\hline
\end{tabular}




\begin{tabular}{|c|c|c|c|c|c|c|}
\hline \multirow{3}{*}{$T \times G P_{-}$size $_{\text {Top }}$} & $(0.071)$ & $(0.044)$ & $(0.105)$ & $(0.049)$ & $(0.054)$ & $(0.033)^{*}$ \\
\hline & -0.056 & 0.072 & -0.115 & 0.081 & 0.073 & -0.072 \\
\hline & $(0.071)$ & $(0.042)^{*}$ & $(0.104)$ & $(0.049)^{*}$ & $(0.049)$ & $(0.036)^{* *}$ \\
\hline Observations & 1433 & 1433 & 1359 & 1359 & 702 & 657 \\
\hline Adjusted R-squared & 0.055 & 0.049 & 0.062 & 0.049 & 0.095 & 0.027 \\
\hline
\end{tabular}

Panel B. PME performance of alternative vehicle as dependent variable.

\begin{tabular}{|c|c|c|c|c|c|c|}
\hline \multirow[b]{2}{*}{ Variables } & \multicolumn{4}{|c|}{ All Alternative vehicles } & \multirow{2}{*}{$\begin{array}{c}\text { Discretionary } \\
\text { Weighted }\end{array}$} & \multirow{2}{*}{$\begin{array}{c}\text { GP-Directed } \\
\text { Weighted }\end{array}$} \\
\hline & Unweighted & Weighted & Unweighted & Weighted & & \\
\hline \multirow[t]{2}{*}{ Vehicle_type $_{\text {Discretionary }}$} & -0.809 & -1.019 & -0.559 & -0.777 & & \\
\hline & $(0.269)^{* * *}$ & $(0.469)^{* *}$ & $(0.272)^{* *}$ & $(0.434)^{*}$ & & \\
\hline \multirow[t]{2}{*}{ GP_region Europe } & -0.221 & -0.067 & -0.278 & -0.295 & -2.022 & 0.298 \\
\hline & $(0.461)$ & $(0.645)$ & $(0.493)$ & $(0.692)$ & $(1.276)$ & $(0.386)$ \\
\hline \multirow[t]{2}{*}{ GP_region $_{\text {RoW }}$} & -0.093 & -0.154 & -0.584 & -0.073 & 1.951 & -1.418 \\
\hline & $(0.903)$ & $(0.706)$ & $(0.588)$ & $(0.471)$ & $(0.849)^{* *}$ & $(0.580)^{* *}$ \\
\hline \multirow[t]{2}{*}{$G P_{-}$strategy $y_{V C}$} & -0.254 & -0.462 & 0.197 & -0.030 & 1.299 & -0.633 \\
\hline & $(0.357)$ & $(0.488)$ & $(0.352)$ & $(0.506)$ & $(1.113)$ & $(0.421)$ \\
\hline \multirow[t]{2}{*}{$G P_{-}$strategy $y_{D e b t}$} & -0.618 & -0.765 & -0.687 & -0.693 & -0.578 & -0.992 \\
\hline & $(0.289)^{* *}$ & $(0.646)$ & $(0.309)^{* *}$ & $(0.758)$ & $(1.221)$ & $(0.510)^{*}$ \\
\hline \multirow[t]{2}{*}{$G P \_s i z e_{\text {Middle }}$} & 1.218 & -0.910 & 1.637 & -2.218 & -0.794 & 0.975 \\
\hline & $(1.580)$ & (1.093) & $(2.416)$ & $(1.075)^{* *}$ & $(1.327)$ & $(1.001)$ \\
\hline \multirow[t]{2}{*}{$G P_{-} \operatorname{size}_{\text {Top }}$} & 1.906 & -1.004 & 2.655 & -2.275 & -2.002 & 1.152 \\
\hline & $(1.567)$ & $(1.062)$ & $(2.384)$ & $(1.030)^{* *}$ & $(0.989)^{* *}$ & $(0.948)$ \\
\hline \multirow[t]{2}{*}{$G P \_p r i o r_{-} 5 y r_{-} P M E$} & & & 0.290 & 0.375 & 0.925 & 0.163 \\
\hline & & & $(0.065)^{* * *}$ & $(0.123)^{* * *}$ & $(0.252)^{* * *}$ & $(0.057)^{* * *}$ \\
\hline \multirow[t]{2}{*}{$T$} & 0.041 & -0.061 & 0.082 & -0.093 & -0.039 & 0.012 \\
\hline & $(0.058)$ & $(0.035)^{*}$ & $(0.086)$ & $(0.035)^{* * *}$ & $(0.033)$ & $(0.033)$ \\
\hline \multirow[t]{2}{*}{$T \times$ Vehicle_type $e_{\text {Discretionary }}$} & 0.028 & 0.034 & 0.020 & 0.026 & & \\
\hline & $(0.009)^{* * *}$ & $(0.014)^{* *}$ & $(0.009)^{* *}$ & $(0.013)^{* *}$ & & \\
\hline \multirow[t]{2}{*}{$T \times G P \_r e g i o n_{\text {Europe }}$} & 0.009 & 0.008 & 0.011 & 0.015 & 0.065 & -0.005 \\
\hline & $(0.015)$ & $(0.023)$ & $(0.016)$ & $(0.024)$ & $(0.044)$ & $(0.013)$ \\
\hline \multirow[t]{2}{*}{$T \times G P_{-}$region ${ }_{R o W}$} & 0.001 & 0.003 & 0.015 & -0.001 & -0.060 & 0.040 \\
\hline & $(0.027)$ & $(0.021)$ & $(0.018)$ & $(0.015)$ & $(0.027)^{* *}$ & $(0.018)^{* *}$ \\
\hline \multirow[t]{2}{*}{$T \times G P_{-}$strategy $y_{V C}$} & 0.004 & 0.011 & -0.009 & -0.003 & -0.044 & 0.018 \\
\hline & $(0.011)$ & $(0.017)$ & $(0.011)$ & $(0.017)$ & $(0.036)$ & $(0.013)$ \\
\hline \multirow[t]{2}{*}{$T \times G P_{-}$strategy $y_{\text {Debt }}$} & 0.017 & 0.023 & 0.019 & 0.021 & 0.021 & 0.029 \\
\hline & $(0.010)^{*}$ & $(0.021)$ & $(0.010)^{*}$ & $(0.025)$ & $(0.041)$ & $(0.015)^{*}$ \\
\hline \multirow[t]{2}{*}{$T \times G P_{-}$size $_{\text {Middle }}$} & -0.045 & 0.037 & -0.066 & 0.083 & 0.029 & -0.020 \\
\hline & $(0.059)$ & $(0.035)$ & $(0.088)$ & $(0.036)^{* *}$ & $(0.043)$ & $(0.034)$ \\
\hline \multirow[t]{2}{*}{$T \times G P_{-} s i z e_{T o p}$} & -0.068 & 0.039 & -0.099 & 0.081 & 0.058 & -0.028 \\
\hline & $(0.058)$ & $(0.034)$ & $(0.087)$ & $(0.034)^{* *}$ & $(0.032)^{*}$ & $(0.033)$ \\
\hline Observations & 1433 & 1433 & 1359 & 1359 & 702 & 657 \\
\hline
\end{tabular}


Table 16: Breakdown of Vehicle Formation by LP Type. Note one vehicle may have multiple LPs.

Panel A. Investment counts by vehicle structure and LP type.

\begin{tabular}{crrrr}
\hline & \multicolumn{3}{c}{ Vehicle type } \\
\hline LP_TYPE & Main & Discretionary & GP-Directed & Grand Total \\
FoF & 1730 & 63 & 168 & 1961 \\
& $(8.8 \%)$ & $(0.3 \%)$ & $(0.9 \%)$ & $(9.9 \%)$ \\
Foundation \& Endowment & 1424 & 119 & 123 & 1666 \\
Insurance \& Financial & $(7.2 \%)$ & $(0.6 \%)$ & $(0.6 \%)$ & $(8.4 \%)$ \\
institution & 6280 & 808 & 1535 & 8623 \\
Private Pension & $(31.8 \%)$ & $(4.1 \%)$ & $(7.8 \%)$ & $(43.6 \%)$ \\
& 717 & 43 & 73 & 833 \\
Public Pension & $(3.6 \%)$ & $(0.3 \%)$ & $(0.4 \%)$ & $(4.2 \%)$ \\
& 4576 & 640 & 387 & 5603 \\
Sovereign Wealth Fund & $(23.2 \%)$ & $(3.2 \%)$ & $(2.0 \%)$ & $(28.3 \%)$ \\
& 826 & 127 & 125 & 1078 \\
Grand Total & $(4.2 \%)$ & $(0.6 \%)$ & $(0.6 \%)$ & $(5.5 \%)$ \\
& 15553 & 1800 & 2411 & 19764 \\
& $(78.7 \%)$ & $(9.1 \%)$ & $(12.2 \%)$ & $(100.0 \%)$ \\
\hline
\end{tabular}

Panel B. USD commitment (Millions) amount by LP type and vehicle structure

\begin{tabular}{crrrr}
\hline LP_TYPE & \multicolumn{3}{c}{ Vehicle type } \\
FoF & Main & Discretionary & GP-Directed & Grand Total \\
& $\$ 21,897$ & $\$ 948$ & $\$ 4,996$ & $\$ 27,841$ \\
Foundation \& Endowment & $(4.1 \%)$ & $(0.2 \%)$ & $(0.9 \%)$ & $(5.2 \%)$ \\
Insurance \& Financial & $\$ 21,383$ & $\$ 2,756$ & $\$ 3,529$ & $\$ 27,668$ \\
institution & $(4.0 \%)$ & $(0.5 \%)$ & $(0.7 \%)$ & $(5.2 \%)$ \\
Private Pension & $\$ 58,794$ & $\$ 3,426$ & $\$ 10,833$ & $\$ 73,053$ \\
& $(11.1 \%)$ & $(0.6 \%)$ & $(2.0 \%)$ & $(13.7 \%)$ \\
Public Pension & $\$ 18,345$ & $\$ 2,702$ & $\$ 2,592$ & $\$ 23,639$ \\
& $(3.4 \%)$ & $(0.5 \%)$ & $(0.5 \%)$ & $(4.4 \%)$ \\
Sovereign Wealth Fund & $\$ 239,949$ & $\$ 17,441$ & $\$ 13,789$ & $\$ 271,179$ \\
Grand Total & $(45.1 \%)$ & $(3.3 \%)$ & $(2.6 \%)$ & $(51.0 \%)$ \\
& $\$ 83,823$ & $\$ 10,601$ & $\$ 14,109$ & $\$ 108,533$ \\
& $(15.8 \%)$ & $(2.0 \%)$ & $(2.7 \%)$ & $(20.4 \%)$ \\
& $\$ 444,191$ & $\$ 37,874$ & $\$ 49,848$ & $\$ 531,913$ \\
\end{tabular}


Table 17: Breakdown of Vehicle Formation by LP Size. Note, one vehicle may have multiple LPs.

Panel A. Investment counts by vehicle structure and LP commitment size tercile.

\begin{tabular}{crrrr}
\hline \multicolumn{5}{c}{ LP commitment size tercile } \\
\hline Vehicle type & Bottom & Middle & Top & Grand Total \\
Main & $355(1.8 \%)$ & $1737(8.8 \%)$ & $13461(68.1 \%)$ & $15553(78.7 \%)$ \\
Discretionary & $14(0.1 \%)$ & $113(0.6 \%)$ & $1673(8.5 \%)$ & $1800(9.1 \%)$ \\
GP-Directed & $41(0.2 \%)$ & $219(1.1 \%)$ & $2151(10.9 \%)$ & $2411(12.2 \%)$ \\
Grand Total & $410(2.1 \%)$ & $2069(10.5 \%)$ & $17285(87.5 \%)$ & $19764(100.0 \%)$ \\
\hline
\end{tabular}

Panel B. USD commitment (Millions) amount by LP commitment size tercile and vehicle structure.

\begin{tabular}{crrrr}
\hline \multicolumn{5}{c}{ LP commitment size tercile } \\
\hline Vehicle type & Bottom & Middle & Top & Grand Total \\
Main & $\$ 2,605(0.5 \%)$ & $\$ 22,451(4.2 \%)$ & $\$ 419,135(78.8 \%)$ & $\$ 444,191(83.5 \%)$ \\
Discretionary & $\$ 341(0.1 \%)$ & $\$ 3,232(0.6 \%)$ & $\$ 34,301(6.4 \%)$ & $\$ 37,874(7.1 \%)$ \\
GP-Directed & $\$ 579(0.1 \%)$ & $\$ 3,850(0.7 \%)$ & $\$ 45,419(8.5 \%)$ & $\$ 49,848(9.4 \%)$ \\
Grand Total & $\$ 3,525(0.7 \%)$ & $\$ 29,533(5.6 \%)$ & $\$ 498,855(93.8 \%)$ & $\$ 531,913(100.0 \%)$ \\
\hline
\end{tabular}

Table 18: Breakdown of Vehicle Formation by LP Geography.

Panel A. Investment counts by vehicle structure and LP Geography.

\begin{tabular}{crrrr}
\hline \multicolumn{5}{c}{ Region } \\
\hline Vehicle type & Europe & NA & RoW & Grand Total \\
Main & $2150(10.9 \%)$ & $12303(62.2 \%)$ & $1100(5.6 \%)$ & $15553(78.7 \%)$ \\
Discretionary & $182(0.9 \%)$ & $1487(7.5 \%)$ & $131(0.7 \%)$ & $1800(9.1 \%)$ \\
GP-Directed & $296(1.5 \%)$ & $1963(9.9 \%)$ & $152(0.8 \%)$ & $2411(12.2 \%)$ \\
Grand Total & $2628(13.3 \%)$ & $15753(79.7 \%)$ & $1383(7.0 \%)$ & $19764(100.0 \%)$ \\
\hline
\end{tabular}

Panel C. USD commitment (Millions) amount by LP Geography and vehicle structure.

\begin{tabular}{crrrr}
\hline \multicolumn{3}{c}{ Region } & RoW & Grand Total \\
\hline Vehicle type & Europe & NA & $\$ 88,349$ & $\$ 444,190$ \\
Main & $\$ 27,671$ & $\$ 328,170$ & $(16.6 \%)$ & $(83.5 \%)$ \\
& $(5.2 \%)$ & $(61.7 \%)$ & $\$ 10,661$ & $\$ 37,874$ \\
Discretionary & $\$ 3,713$ & $\$ 23,500$ & $(2.0 \%)$ & $(7.1 \%)$ \\
& $(0.7 \%)$ & $(4.4 \%)$ & $\$ 14,724$ & $\$ 49,848$ \\
GP-Directed & $\$ 7,044$ & $\$ 28,080$ & $(2.8 \%)$ & $(9.4 \%)$ \\
& $(1.3 \%)$ & $(5.3 \%)$ & $\$ 113,734$ & $\$ 531,912$ \\
Grand Total & $\$ 38,428$ & $\$ 379,750$ & $(21.4 \%)$ & $(100.0 \%)$ \\
\hline
\end{tabular}


Table 19: Adjusted Excess PME Performance (Russel 3000 KS PME) of Alternative Vehicles by LP Type. Excess PMEs are winsorized at the $0.5^{\text {th }}$ and $99.5^{\text {th }}$ percentiles. One vehicle may have more than one LP.

\begin{tabular}{crrrrrrr}
\hline LP type & Vehicle type & N & $\begin{array}{r}\text { Weighted } \\
\text { Average }\end{array}$ & p-Value & Average & p-Value & Median \\
\hline FoF & Discretionary & 35 & -0.144 & 0.025 & -0.107 & 0.385 & -0.075 \\
& GP-Directed & 89 & -0.106 & 0.088 & -0.078 & 0.374 & -0.021 \\
Foundation \& & Discretionary & 53 & 0.064 & 0.420 & 0.026 & 0.773 & -0.039 \\
Endowment & GP-Directed & 74 & -0.028 & 0.319 & 0.002 & 0.949 & 0.005 \\
Insurance \& & Discretionary & 162 & 0.177 & 0.002 & 0.247 & 0.000 & 0.081 \\
Financial institution & GP-Directed & 390 & 0.013 & 0.677 & 0.050 & 0.187 & 0.020 \\
Private Pension & Discretionary & 29 & 0.195 & 0.002 & -0.041 & 0.723 & 0.027 \\
Public Pension & GP-Directed & 54 & -0.001 & 0.985 & -0.045 & 0.567 & -0.016 \\
Siscretionary & 390 & -0.083 & 0.205 & -0.044 & 0.470 & 0.038 \\
Sovereign Wealth & GP-Directed & 120 & -0.065 & 0.122 & 0.023 & 0.606 & 0.013 \\
Fund & Discretionary & 102 & 0.082 & 0.093 & -0.005 & 0.933 & -0.086 \\
& GP-Directed & 100 & -0.213 & 0.004 & -0.220 & 0.004 & -0.063 \\
\hline
\end{tabular}

Table 20: Adjusted Excess PME Performance of Alternative Vehicles by LP Size. Excess PMEs are winsorized at the $0.5^{\text {th }}$ and $99.5^{\text {th }}$ percentiles.

\begin{tabular}{clrrrrrr}
\hline LP size & Vehicle type & $\mathbf{N}$ & Weighted Average & p-Value & Average & p-Value & Median \\
\hline Bottom & Discretionary & 10 & -0.310 & 0.010 & 0.087 & 0.689 & 0.099 \\
Bottom & GP-Directed & 35 & -0.005 & 0.945 & -0.102 & 0.177 & -0.015 \\
Middle & Discretionary & 78 & 0.090 & 0.112 & -0.050 & 0.630 & -0.087 \\
Middle & GP-Directed & 152 & -0.080 & 0.067 & -0.020 & 0.755 & -0.001 \\
Top & Discretionary & 665 & 0.011 & 0.781 & 0.039 & 0.310 & 0.029 \\
Top & GP-Directed & 585 & -0.094 & 0.000 & -0.001 & 0.981 & 0.004 \\
\hline
\end{tabular}

Table 21: Adjusted Excess PME Performance of Alternative Vehicles by LP Geography. NA (i.e. North America) includes US and Canada. Excess PMEs are winsorized at the $0.5^{\text {th }}$ and $99.5^{\text {th }}$ percentiles.

\begin{tabular}{clrrrrrr}
\hline LP region & Vehicle type & $\mathbf{N}$ & Weighted Average & p-Value & Average & p-Value & Median \\
\hline NA & Discretionary & 587 & -0.041 & 0.397 & 0.012 & 0.781 & 0.013 \\
NA & GP-Directed & 523 & -0.041 & 0.056 & 0.009 & 0.747 & 0.005 \\
Europe & Discretionary & 78 & 0.177 & 0.000 & 0.218 & 0.013 & 0.159 \\
Europe & GP-Directed & 139 & -0.023 & 0.588 & 0.063 & 0.383 & 0.000 \\
RoW & Discretionary & 104 & 0.081 & 0.095 & -0.010 & 0.854 & -0.086 \\
RoW & GP-Directed & 115 & -0.205 & 0.002 & -0.183 & 0.005 & -0.050 \\
\hline
\end{tabular}


Table 22. Analysis of Alternative Vehicle Performance by GP and LP Characteristics. Each investment by an individual LP in an alternative vehicle is an observation; the dependent variable is their Adjusted Excess PME Performance. Weighted regressions use the individual capital commitments as weights. GP and LP prior five-year mean PME are averages, weighted by commitments, over the prior five years. The reference categories are Fund of Funds for LP type, North America (US \& Canada) for LP Region, and bottom tercile for LP Size. T is a time trend variable equal to vintage year less 1980 . Standard errors are clustered by GP and LP and shown in parentheses. $* * *$ and $* * *$ denote statistical significance at the $10 \%, 5 \%$ and $1 \%$ level, respectively. Excess PMEs are winsorized at the $0.5^{\text {th }}$ and $99.5^{\text {th }}$ percentiles.

\begin{tabular}{|c|c|c|c|c|c|c|}
\hline \multirow[b]{2}{*}{ Variables } & \multicolumn{4}{|c|}{ All alternative vehicles } & \multirow{2}{*}{$\begin{array}{c}\text { Discretionary } \\
\text { Weighted }\end{array}$} & \multirow{2}{*}{$\begin{array}{c}\text { GP-Directed } \\
\text { Weighted }\end{array}$} \\
\hline & Unweighted & Weighted & Unweighted & Weighted & & \\
\hline \multirow[t]{2}{*}{ Vehicle_type discretionary } & 0.195 & -0.137 & 0.179 & -0.194 & & \\
\hline & $(0.136)$ & $(0.351)$ & $(0.161)$ & $(0.370)$ & & \\
\hline \multirow[t]{2}{*}{$L P_{-} t_{y p e_{\text {foundation } \& \text { endowment }}}$} & 0.230 & 0.261 & 0.244 & 0.341 & -0.269 & 0.174 \\
\hline & $(0.084)^{* * *}$ & $(0.151)^{*}$ & $(0.112)^{* *}$ & $(0.173)^{* *}$ & $(0.446)$ & $(0.121)$ \\
\hline \multirow[t]{2}{*}{$L P_{-}$type $_{\text {insurance } \& \text { financial institution }}$} & 0.223 & 0.308 & 0.215 & 0.198 & -0.490 & 0.219 \\
\hline & $(0.057)^{* * *}$ & $(0.091)^{* * *}$ & $(0.094)^{* *}$ & $(0.174)$ & $(0.406)$ & $(0.111)^{* *}$ \\
\hline \multirow[t]{2}{*}{$L P_{-}$type private pension } & 0.218 & 0.309 & 0.229 & 0.336 & -0.202 & 0.256 \\
\hline & $(0.088)^{* *}$ & $(0.112)^{* * *}$ & $(0.116)^{* *}$ & $(0.119)^{* * *}$ & $(0.483)$ & $(0.066)^{* * *}$ \\
\hline \multirow[t]{2}{*}{ LP_type $e_{\text {public pension }}$} & 0.189 & -0.097 & 0.172 & 0.032 & -0.528 & 0.186 \\
\hline & $(0.105)^{*}$ & $(0.267)$ & $(0.096)^{*}$ & $(0.180)$ & $(0.446)$ & $(0.177)$ \\
\hline \multirow[t]{2}{*}{$L P_{-}$type $e_{\text {soverign wealth fund }}$} & -0.196 & 0.033 & -0.145 & 0.129 & -1.943 & -0.070 \\
\hline & $(0.186)$ & $(0.149)$ & $(0.176)$ & $(0.215)$ & $(1.273)$ & $(0.164)$ \\
\hline \multirow[t]{2}{*}{ LP_region Europe $_{1}$} & 0.191 & 0.247 & 0.176 & 0.096 & 0.013 & 0.100 \\
\hline & $(0.129)$ & $(0.162)$ & $(0.113)$ & $(0.140)$ & $(0.256)$ & $(0.104)$ \\
\hline \multirow[t]{2}{*}{ LP_region $_{\text {RoW }}$} & -0.017 & -0.059 & -0.049 & -0.102 & 1.138 & 0.133 \\
\hline & $(0.183)$ & $(0.173)$ & $(0.208)$ & $(0.221)$ & $(1.128)$ & $(0.163)$ \\
\hline \multirow[t]{2}{*}{$L P \_s i z e_{\text {middle }}$} & 0.044 & 0.351 & 0.011 & -0.030 & -1.664 & -0.018 \\
\hline & $(0.145)$ & $(0.219)$ & $(0.140)$ & $(0.227)$ & $(0.920)^{*}$ & $(0.120)$ \\
\hline \multirow[t]{2}{*}{$L P_{-}$size $_{\text {top }}$} & 0.076 & 0.430 & 0.048 & 0.007 & -0.812 & 0.086 \\
\hline & $(0.113)$ & $(0.213)^{* *}$ & $(0.127)$ & $(0.250)$ & $(0.643)$ & $(0.098)$ \\
\hline \multirow[t]{2}{*}{$L P \_p r i o r_{-} 5 y r_{-} P M E$} & & & 0.127 & 1.849 & 4.679 & 0.212 \\
\hline & & & $(0.088)$ & $(0.877)^{* *}$ & $(1.632)^{* * *}$ & $(0.086)^{* *}$ \\
\hline \multirow[t]{2}{*}{$G P \_r e g i o n_{\text {Europe }}$} & 0.301 & 0.637 & 0.328 & 0.610 & 1.194 & 0.229 \\
\hline & $(0.109)^{* * *}$ & $(0.301)^{* *}$ & $(0.114)^{* * *}$ & $(0.257)^{* *}$ & $(0.385)^{* * *}$ & $(0.113)^{* *}$ \\
\hline \multirow[t]{2}{*}{ GP_region $_{\text {RoW }}$} & 1.814 & 0.802 & 1.951 & 0.907 & 0.077 & 1.755 \\
\hline & $(1.362)$ & $(0.720)$ & $(1.480)$ & $(0.755)$ & $(0.441)$ & $(1.460)$ \\
\hline \multirow[t]{2}{*}{$G_{-}$size $_{\text {Middle }}$} & 0.101 & -0.226 & -0.074 & -0.424 & -1.876 & -0.193 \\
\hline & $(0.236)$ & $(0.208)$ & $(0.267)$ & $(0.304)$ & $(0.701)^{* * *}$ & $(0.257)$ \\
\hline \multirow[t]{2}{*}{$G P_{-} \operatorname{size}_{T o p}$} & 0.179 & -0.076 & 0.116 & -0.229 & -2.026 & 0.139 \\
\hline & $(0.232)$ & $(0.175)$ & $(0.300)$ & $(0.335)$ & $(0.769)^{* * *}$ & $(0.162)$ \\
\hline
\end{tabular}




\begin{tabular}{|c|c|c|c|c|c|c|}
\hline \multirow[t]{2}{*}{$G P_{-}$strategy $y_{V C}$} & 0.438 & 0.378 & 0.442 & 0.482 & 0.428 & 0.470 \\
\hline & $(0.325)$ & $(0.276)$ & $(0.304)$ & $(0.272)^{*}$ & $(0.318)$ & $(0.327)$ \\
\hline \multirow[t]{2}{*}{$G P_{-}$strategy $y_{\text {Debt }}$} & -0.037 & 0.267 & -0.050 & 0.316 & 0.737 & 0.007 \\
\hline & $(0.209)$ & $(0.241)$ & $(0.204)$ & $(0.228)$ & $(0.434)^{*}$ & $(0.106)$ \\
\hline \multirow[t]{2}{*}{ GP_prior_5yr_PME } & & & -0.217 & -0.081 & 0.080 & -0.435 \\
\hline & & & $(0.329)$ & $(0.355)$ & $(1.207)$ & $(0.179)^{* *}$ \\
\hline \multirow[t]{2}{*}{$T$} & 0.072 & 0.253 & 0.069 & 0.275 & 0.784 & -0.077 \\
\hline & $(0.064)$ & $(0.204)$ & $(0.084)$ & $(0.217)$ & $(0.293)^{* * *}$ & $(0.105)$ \\
\hline Observations & 3615 & 3615 & 3364 & 3364 & 1468 & 1896 \\
\hline Adjusted R-squared & 0.062 & 0.043 & 0.068 & 0.090 & 0.222 & 0.091 \\
\hline
\end{tabular}


Table 23. Analysis of LP and GP matching in alternative vehicles. Each investment by an individual LP in an alternative vehicle is an observation; the dependent variable is their PME performance. Weighted regressions use the individual capital commitments as weights. The reference categories are buyout for GP strategy and bottom tercile for GP size. In Columns 1, 3, and 5, we use the average performance over the total VCPE portfolio and the entire time period an LP or GP is in our sample. We then classify LPs and GPs into above median versus below median performers. We form four dummies to characterize the match between the LP and the GP: (1) LP and GP above median, (2) LP and GP below median, (3) LP above median and GP above, and (4) vice versa. In the even columns, we repeat the same regression set-up, but use as the performance measure the average volume-weighted PME in the five years prior to the inception of the alternative vehicle. We include GP fixed effects here, since this measure of performance varies over time. Standard errors are shown in parentheses. $*, * *$ and $* * *$ denote statistical significance at the $10 \%, 5 \%$ and $1 \%$ level, respectively. PMEs are winsorized at the 99th percentile.

\begin{tabular}{|c|c|c|c|c|c|c|}
\hline Variables & \multicolumn{2}{|c|}{ All alternative vehicles } & \multicolumn{2}{|c|}{ Discretionary } & \multicolumn{2}{|c|}{ GP-Directed } \\
\hline \multirow[t]{2}{*}{ GP_size $_{\text {Middle }}$} & 0.229 & & -0.069 & & 0.424 & \\
\hline & $(0.312)$ & & $(0.649)$ & & $(0.294)$ & \\
\hline \multirow[t]{2}{*}{$G P_{-}$size $_{\text {Top }}$} & 0.149 & & -0.309 & & 0.437 & \\
\hline & $(0.306)$ & & $(0.637)$ & & $(0.288)$ & \\
\hline \multirow[t]{2}{*}{$G P_{-}{ }_{s t r a t e g} y_{V C}$} & 0.025 & & -0.053 & & 0.116 & \\
\hline & $(0.043)$ & & $(0.080)$ & & $(0.044)^{* * *}$ & \\
\hline \multirow[t]{2}{*}{ GP_strategy $y_{\text {Debt }}$} & 0.002 & & 0.167 & & -0.100 & \\
\hline & $(0.033)$ & & $(0.061)^{* * *}$ & & $(0.034)^{* * *}$ & \\
\hline \multirow[t]{2}{*}{$L P \_P M E(+) G P_{-} P M E(-)$} & 0.181 & 0.023 & 0.246 & 0.082 & 0.174 & 0.007 \\
\hline & $(0.039)^{* * *}$ & $(0.027)$ & $(0.083)^{* * *}$ & $(0.062)$ & $(0.037)^{* * *}$ & $(0.025)$ \\
\hline \multirow[t]{2}{*}{$L P \_P M E(-) G P_{-} P M E(+)$} & 0.185 & 0.141 & 0.274 & 0.339 & 0.162 & 0.042 \\
\hline & $(0.034)^{* * *}$ & $(0.034)^{* * *}$ & $(0.073)^{* * *}$ & $(0.076)^{* * *}$ & $(0.032)^{* * *}$ & $(0.031)$ \\
\hline \multirow[t]{2}{*}{$L P_{-} P M E(+) G P \_P M E(+)$} & 0.376 & 0.155 & 0.588 & 0.003 & 0.263 & 0.143 \\
\hline & $(0.034)^{* * *}$ & $(0.030)^{* * *}$ & $(0.072)^{* * *}$ & $(0.071)$ & $(0.033)^{* * *}$ & $(0.027)^{* * *}$ \\
\hline GP_fixed_effects & No & Yes & No & Yes & No & Yes \\
\hline Observations & 3615 & 3364 & 1544 & 1468 & 2071 & 1896 \\
\hline Adjusted R-squared & 0.041 & 0.307 & 0.064 & 0.346 & 0.036 & 0.439 \\
\hline
\end{tabular}




\section{Appendix A: Variable Definitions}

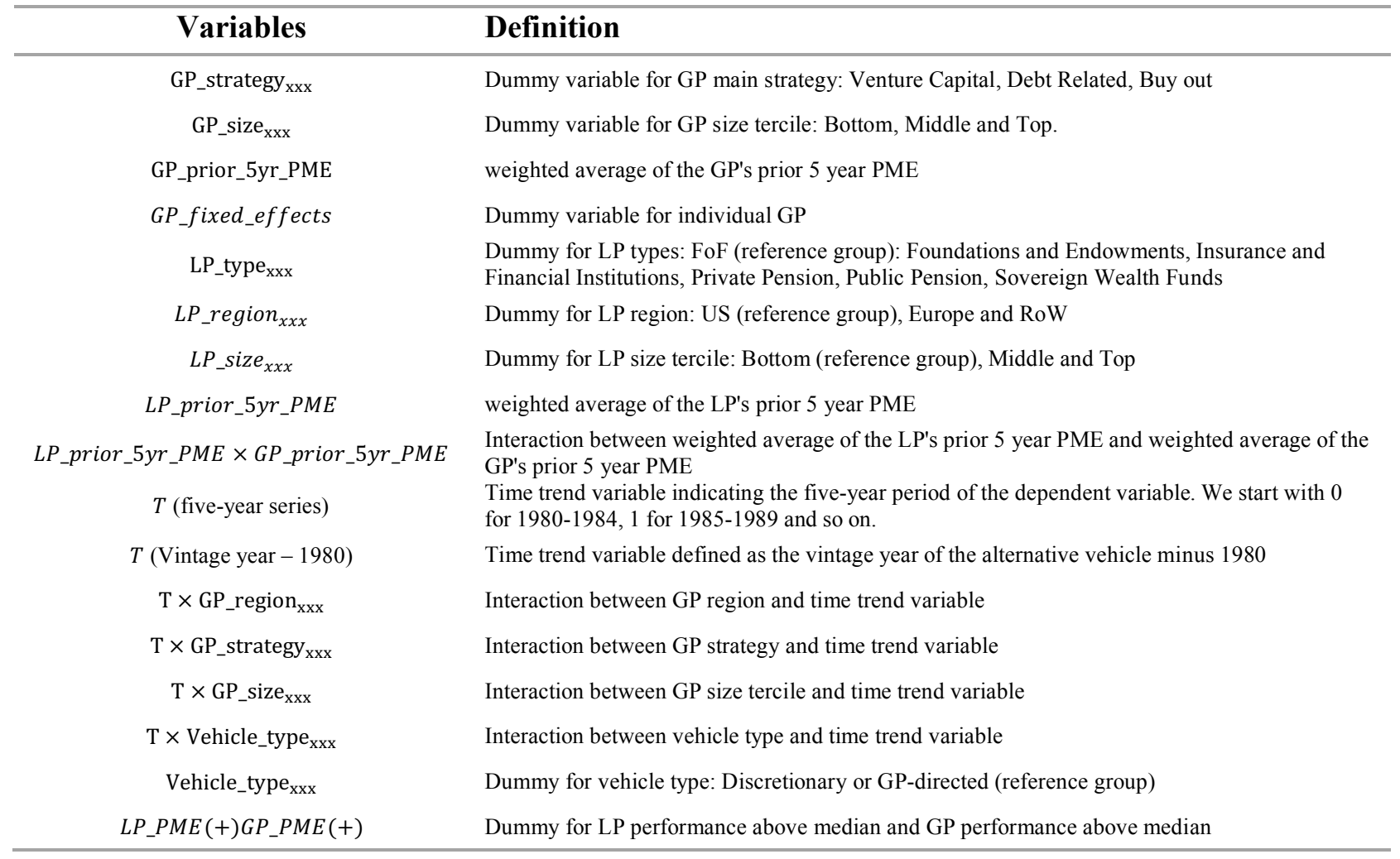


Appendix B: Replicating the main fund performance calculations of Harris, et al. (2016). S\&P 500 PME of North American GP's buyout and venture capital main funds.

\begin{tabular}{|c|c|c|c|c|c|c|c|c|}
\hline & \multicolumn{4}{|c|}{ Buyout } & \multicolumn{4}{|c|}{ Venture Capital } \\
\hline & & Media & Mea & Weighted & & Media & Mea & Weighted \\
\hline Vintage year & $\mathrm{N}$ & $\mathrm{n}$ & $\mathrm{n}$ & average & $\mathrm{N}$ & $\mathrm{n}$ & $\mathrm{n}$ & average \\
\hline 1985 & 1 & 0.93 & 0.93 & 0.93 & & & & \\
\hline 1986 & & & & & 1 & 1.58 & 1.58 & 1.58 \\
\hline 1987 & 1 & 0.98 & 0.98 & 0.98 & & & & \\
\hline 1988 & 7 & 1.01 & 1.22 & 1.00 & 8 & 1.28 & 1.12 & 1.35 \\
\hline 1989 & 3 & 1.17 & 1.29 & 1.69 & 8 & 1.12 & 1.24 & 1.20 \\
\hline 1990 & 6 & 0.93 & 0.88 & 0.87 & 7 & 1.14 & 1.55 & 1.79 \\
\hline 1991 & 6 & 1.09 & 1.15 & 1.22 & 5 & 0.88 & 0.72 & 0.61 \\
\hline 1992 & 8 & 1.24 & 1.21 & 1.13 & 9 & 1.15 & 1.65 & 1.48 \\
\hline 1993 & 10 & 1.07 & 1.36 & 1.13 & 13 & 1.13 & 1.33 & 1.46 \\
\hline 1994 & 17 & 1.07 & 1.20 & 1.49 & 16 & 1.47 & 2.36 & 1.37 \\
\hline 1995 & 13 & 0.98 & 1.22 & 1.17 & 9 & 1.68 & 2.05 & 2.69 \\
\hline 1996 & 19 & 1.28 & 1.33 & 1.35 & 12 & 1.52 & 2.35 & 1.49 \\
\hline 1997 & 37 & 1.44 & 1.46 & 1.39 & 21 & 1.27 & 1.69 & 1.13 \\
\hline 1998 & 52 & 1.33 & 1.43 & 1.39 & 30 & 1.28 & 2.20 & 1.08 \\
\hline 1999 & 45 & 1.39 & 1.26 & 1.22 & 56 & 0.67 & 0.77 & 0.61 \\
\hline 2000 & 49 & 1.32 & 1.48 & 1.48 & 74 & 0.76 & 0.98 & 0.84 \\
\hline 2001 & 47 & 1.46 & 1.44 & 1.59 & 36 & 0.92 & 0.96 & 0.92 \\
\hline 2002 & 40 & 1.37 & 1.45 & 1.35 & 21 & 0.65 & 0.73 & 0.70 \\
\hline 2003 & 42 & 1.36 & 1.53 & 1.54 & 15 & 0.81 & 3.03 & 0.87 \\
\hline 2004 & 58 & 1.30 & 1.26 & 1.40 & 29 & 0.78 & 1.47 & 0.95 \\
\hline 2005 & 84 & 1.02 & 1.06 & 1.10 & 52 & 0.87 & 1.24 & 1.18 \\
\hline 2006 & $\begin{array}{l}96 \\
11\end{array}$ & 0.98 & 1.17 & 0.98 & 67 & 0.86 & 1.08 & 0.97 \\
\hline 2007 & $\begin{array}{r}6 \\
10\end{array}$ & 0.98 & 1.23 & 1.02 & 63 & 0.92 & 1.02 & 0.97 \\
\hline 2008 & 1 & 0.91 & 0.92 & 0.90 & 52 & 0.87 & 1.07 & 1.02 \\
\hline 2009 & 41 & 0.96 & 1.02 & 0.99 & 30 & 1.05 & 1.11 & 1.03 \\
\hline 2010 & 45 & 1.00 & 0.94 & 0.75 & 35 & 1.11 & 1.17 & 1.21 \\
\hline & 94 & & & & 66 & & & \\
\hline Average & 4 & 1.14 & 1.22 & 1.20 & 9 & 1.07 & 1.44 & 1.19 \\
\hline Average & 71 & & & & 47 & & & \\
\hline $2000 s$ & 9 & 1.15 & 1.23 & 1.19 & 4 & 0.87 & 1.26 & 0.97 \\
\hline Average & 21 & & & & 17 & & & \\
\hline $1990 s$ & 3 & 1.18 & 1.25 & 1.24 & 8 & 1.22 & 1.67 & 1.37 \\
\hline $\begin{array}{l}\text { Average } \\
\text { 1980s }\end{array}$ & 12 & 1.02 & 1.11 & 1.15 & 17 & 1.33 & 1.31 & 1.38 \\
\hline
\end{tabular}


Appendix C: Tables 3, 4, and 5 without private debt.

Table 3 without private debt GPs

\begin{tabular}{lrrrrr}
\multicolumn{7}{c}{ Russell 3000 KS PME } \\
\hline Vehicle type & $\mathbf{N}$ & $\mathbf{2 5 \%}$ & $\mathbf{5 0 \%}$ & $\mathbf{7 5 \%}$ & Weighted Average PME \\
\hline MAIN & 3126 & 1.25 & 0.97 & 0.76 & 1.03 \\
Main AV-Associated & 605 & 1.25 & 0.99 & 0.77 & 1.02 \\
DISCRETIONARY & 768 & 1.24 & 0.99 & 0.76 & 0.99 \\
GP-DIRECTED & 706 & 1.28 & 1.01 & 0.82 & 0.98 \\
\hline
\end{tabular}

\begin{tabular}{|c|c|c|c|c|c|}
\hline \multicolumn{6}{|c|}{ IRR } \\
\hline Vehicle type & $\mathbf{N}$ & $25 \%$ & $50 \%$ & $75 \%$ & Weighted Average IRR \\
\hline MAIN & 3126 & 0.18 & 0.09 & 0.00 & 0.09 \\
\hline Main AV-Associated & 605 & 0.17 & 0.09 & -0.01 & 0.10 \\
\hline DISCRETIONARY & 768 & 0.25 & 0.10 & -0.02 & 0.08 \\
\hline GP-DIRECTED & 706 & 0.24 & 0.12 & 0.03 & 0.11 \\
\hline
\end{tabular}

TVPI

\begin{tabular}{|c|c|c|c|c|c|}
\hline Vehicle type & $\mathbf{N}$ & $25 \%$ & $50 \%$ & $75 \%$ & Weighted Average TVPI \\
\hline MAIN & 3126 & 1.74 & 1.29 & 0.99 & 1.38 \\
\hline Main AV-Associated & 605 & 1.68 & 1.25 & 0.99 & 1.37 \\
\hline DISCRETIONARY & 768 & 1.56 & 1.15 & 0.94 & 1.27 \\
\hline GP-DIRECTED & 706 & 1.75 & 1.32 & 1.05 & 1.26 \\
\hline
\end{tabular}

Table 4 without private debt GPs

\begin{tabular}{ccccccc}
\hline Vehicle type & $\mathbf{N}$ & Weighted average & $\mathbf{p}$-value & Average & p-value & median \\
\hline All & 1306 & -0.090 & 0.000 & -0.015 & 0.522 & 0.002 \\
Discretionary & 674 & -0.051 & 0.170 & -0.010 & 0.789 & 0.001 \\
GP-Directed & 632 & -0.115 & 0.000 & -0.020 & 0.424 & 0.002 \\
\hline
\end{tabular}

Table 5 without private debt GPs

\begin{tabular}{ccccccc}
\hline Vehicle type & $\mathbf{N}$ & Weighted average & p-value & Average & p-value & median \\
\hline All & 1306 & -0.080 & 0.000 & -0.014 & 0.538 & 0.002 \\
Discretionary & 674 & -0.049 & 0.197 & -0.014 & 0.709 & 0.002 \\
GP-Directed & 632 & -0.100 & 0.000 & -0.014 & 0.560 & 0.001 \\
\hline
\end{tabular}


Appendix D: Table 3, 4, and 5 with vintage years before 2012.

Table 3 with vintage years before 2012

\begin{tabular}{lrrrrr}
\multicolumn{7}{c}{ Russell 3000 KS PME } \\
\hline Vehicle type & $\mathbf{N}$ & $\mathbf{2 5 \%}$ & $\mathbf{5 0 \%}$ & $\mathbf{7 5 \%}$ & Weighted Average PME \\
\hline MAIN & 2447 & 1.33 & 0.99 & 0.72 & 1.05 \\
Main AV-Associated & 430 & 1.35 & 0.98 & 0.71 & 1.03 \\
DISCRETIONARY & 498 & 1.29 & 1.00 & 0.65 & 0.92 \\
GP-DIRECTED & 501 & 1.35 & 1.02 & 0.76 & 1.03 \\
\hline
\end{tabular}

\begin{tabular}{|c|c|c|c|c|c|}
\hline \multicolumn{6}{|c|}{ IRR } \\
\hline Vehicle type & $\mathbf{N}$ & $25 \%$ & $50 \%$ & $75 \%$ & Weighted Average IRR \\
\hline MAIN & 2447 & 0.18 & 0.09 & 0.02 & 0.10 \\
\hline Main AV-Associated & 430 & 0.16 & 0.08 & -0.01 & 0.10 \\
\hline DISCRETIONARY & 498 & 0.27 & 0.09 & -0.02 & 0.04 \\
\hline GP-DIRECTED & 501 & 0.23 & 0.12 & 0.02 & 0.12 \\
\hline
\end{tabular}

TVPI

\begin{tabular}{|c|c|c|c|c|c|}
\hline Vehicle type & $\mathbf{N}$ & $25 \%$ & $50 \%$ & $75 \%$ & Weighted Average TVPI \\
\hline MAIN & 2447 & 1.91 & 1.44 & 1.05 & 1.50 \\
\hline Main AV-Associated & 430 & 1.87 & 1.36 & 0.98 & 1.48 \\
\hline DISCRETIONARY & 498 & 1.78 & 1.20 & 0.88 & 1.32 \\
\hline GP-DIRECTED & 501 & 1.93 & 1.48 & 1.10 & 1.50 \\
\hline
\end{tabular}

Table 4 with vintage years before 2012

\begin{tabular}{clrrrrr}
\hline Vehicle type & N & Weighted average & p-value & \multicolumn{1}{c}{ Average } & \multicolumn{1}{c}{-value } & \multicolumn{1}{c}{ median } \\
\hline All & 953 & -0.166 & 0.000 & -0.040 & 0.149 & 0.000 \\
Discretionary & 461 & -0.287 & 0.000 & -0.087 & 0.082 & -0.025 \\
GP-Directed & 492 & -0.099 & 0.000 & 0.003 & 0.910 & 0.003 \\
\hline
\end{tabular}

Table 5 with vintage years before 2012

\begin{tabular}{clrrrrr}
\hline Vehicle type & N & Weighted average & p-value & \multicolumn{1}{c}{ Average } & p-value & \multicolumn{1}{c}{ median } \\
\hline All & 953 & -0.149 & 0.000 & -0.037 & 0.189 & 0.000 \\
Discretionary & 461 & -0.276 & 0.000 & -0.089 & 0.080 & -0.022 \\
GP-Directed & 492 & -0.077 & 0.002 & 0.012 & 0.670 & 0.003 \\
\hline
\end{tabular}


Appendix E: Tables 3, 4, and 5 without blocker and off-shore funds.

Table 3 without blocker and off-shore funds

\begin{tabular}{lrrrrr}
\multicolumn{7}{c}{ Russell 3000 KS PME } \\
\hline Vehicle type & $\mathbf{N}$ & $\mathbf{2 5 \%}$ & $\mathbf{5 0 \%}$ & $\mathbf{7 5 \%}$ & Weighted Average PME \\
\hline MAIN & 3556 & 1.23 & 0.97 & 0.77 & 1.02 \\
Main AV-Associated & 642 & 1.20 & 0.97 & 0.75 & 1.02 \\
DISCRETIONARY & 829 & 1.22 & 0.99 & 0.77 & 0.99 \\
GP-DIRECTED & 688 & 1.26 & 1.01 & 0.80 & 0.97 \\
\hline
\end{tabular}

\begin{tabular}{|c|c|c|c|c|c|}
\hline \multicolumn{6}{|c|}{ IRR } \\
\hline Vehicle type & $\mathbf{N}$ & $25 \%$ & $50 \%$ & $75 \%$ & Weighted Average IRR \\
\hline MAIN & 3556 & 0.17 & 0.09 & 0.00 & 0.09 \\
\hline Main AV-Associated & 642 & 0.17 & 0.09 & -0.01 & 0.10 \\
\hline DISCRETIONARY & 829 & 0.24 & 0.09 & -0.01 & 0.09 \\
\hline GP-DIRECTED & 688 & 0.24 & 0.12 & 0.03 & 0.11 \\
\hline
\end{tabular}

\begin{tabular}{|c|c|c|c|c|c|}
\hline \multicolumn{6}{|c|}{ TVPI } \\
\hline Vehicle type & $\mathbf{N}$ & $25 \%$ & $50 \%$ & $75 \%$ & Weighted Average TVPI \\
\hline MAIN & 3556 & 1.70 & 1.28 & 1.00 & 1.37 \\
\hline Main AV-Associated & 642 & 1.65 & 1.22 & 0.99 & 1.37 \\
\hline DISCRETIONARY & 829 & 1.55 & 1.16 & 0.95 & 1.26 \\
\hline GP-DIRECTED & 688 & 1.73 & 1.30 & 1.04 & 1.26 \\
\hline
\end{tabular}

Table 4 without blocker and off-shore funds

\begin{tabular}{ccccccc}
\hline Vehicle type & $\mathbf{N}$ & Weighted average & $\mathbf{p}$-value & Average & p-value & median \\
\hline All & 1323 & -0.090 & 0.000 & -0.008 & 0.742 & 0.004 \\
Discretionary & 714 & -0.037 & 0.327 & 0.004 & 0.924 & 0.008 \\
GP-Directed & 609 & -0.132 & 0.000 & -0.021 & 0.422 & 0.004 \\
\hline
\end{tabular}

Table 5 without blocker and off-shore funds

\begin{tabular}{ccccccc}
\hline Vehicle type & $\mathbf{N}$ & Weighted average & p-value & Average & p-value & median \\
\hline All & 1323 & -0.076 & 0.001 & -0.005 & 0.825 & 0.004 \\
Discretionary & 714 & -0.027 & 0.476 & 0.003 & 0.936 & 0.010 \\
GP-Directed & 609 & -0.116 & 0.000 & -0.015 & 0.562 & 0.004 \\
\hline
\end{tabular}

